\title{
A Global Database of Land Surface Parameters at 1-km Resolution in Meteorological and Climate Models
}

\author{
Valéry Masson, Jean-Louis Champeaux, Fabrice Chauvin, Christelle Meriguet, \\ AND ROSELYNE LACAZE \\ CNRM/GAME Météo-France/CNRS, Toulouse, France
}

(Manuscript received 28 January 2002, in final form 9 August 2002)

ABSTRACT

\begin{abstract}
Ecoclimap, a new complete surface parameter global dataset at a $1-\mathrm{km}$ resolution, is presented. It is intended to be used to initialize the soil-vegetation-atmosphere transfer schemes (SVATs) in meteorological and climate models (at all horizontal scales). The database supports the "tile" approach, which is utilized by an increasing number of SVATs. Two hundred and fifteen ecosystems representing areas of homogeneous vegetation are derived by combining existing land cover maps and climate maps, in addition to using Advanced Very High Resolution Radiometer (AVHRR) satellite data. Then, all surface parameters are derived for each of these ecosystems using lookup tables with the annual cycle of the leaf area index (LAI) being constrained by the AVHRR information. The resulting LAI is validated against a large amount of in situ ground observations, and it is also compared to LAI derived from the International Satellite Land Surface Climatology Project (ISLSCP-2) database and the Polarization and Directionality of the Earth's Reflectance (POLDER) satellite. The comparison shows that this new LAI both reproduces values coherent at large scales with other datasets, and includes the high spatial variations owing to the input land cover data at a 1-km resolution. In terms of climate modeling studies, the use of this new database is shown to improve the surface climatology of the ARPEGE climate model.
\end{abstract}

\section{Introduction}

Because the evolution of the atmospheric system, from weather and pollution forecasting to climate, is a major concern of mankind, it has become mandatory to provide a detailed portrait of the physical processes occurring near the ground. Richardson (1922) first noted the importance of the role of the vegetation representation in numerical weather prediction. During recent decades, several investigations have confirmed the strong coupling that exists between the tropospheric airmass circulation and the energy exchanges at the surface of the atmospheric boundary layer (Woodward 1987; Melillo et al. 1995). Recent climate modeling has also focused on the representation of $\mathrm{CO}_{2}$ fluxes between the land surface and the atmosphere (Sellers et al. 1996) in order to explicitly represent the biomass evolution. Thus, there is a need to have a thorough and realistic description of the land surface characteristics in meteorological models, from mesoscale research and numerical weather prediction (NWP) models (describing phenomena of horizontal scale of a few kilometers) to general circulation models (GCMs).

Corresponding author address: Dr. Valéry Masson, CNRM/ GAME, Météo-France/CNRS, 42 avenue Gaspard Coriolis, Toulouse Cedex 31057, France.

E-mail: valery.masson@meteo.fr
In atmospheric models, surface exchanges are parameterized by soil-vegetation-atmosphere transfer (SVAT) schemes. A rather comprehensive list of them can be found in the literature (see the review by Chen et al. 1997b). SVATs need the right allocation of the landwater mask and of the soil-vegetation characteristics for the calculation of the surface fluxes of momentum, heat, and moisture. The latter two are defined by the surface energy budget, which is written as

$$
Q^{*}=Q_{H}+Q_{E}+\Delta Q_{S}
$$

- Here $Q^{*}$ is the net radiation, governed by solar radiation during the day and therefore directly influenced by the albedo, while at night only the infrared longwave radiation budget remains and emissivity becomes important.

- The sensible and latent heat fluxes are $Q_{H}$ and $Q_{E}$, respectively. They are small at night, but utilize almost all the net radiation energy during the day. The larger the $Q_{H}$, the more the temperature will increase in the low atmosphere. The more $Q_{E}$ is significant, the more this temperature increase is limited, with the energy being used to evaporate water. The ratio between the two fluxes, called the Bowen ratio, is then very important and it strongly depends on the vegetation parameters: a large leaf area index (LAI), a large veg- 
etation fraction, a small stomatal resistance (influencing transpiration process through the leaves), and a deep soil reservoir will favor $Q_{E}$. Dry soils or leafless vegetation (which dampens the transpiration process) limit $Q_{E}$ and favor $Q_{H}$.

- Finally, $\Delta Q_{S}$ is the surface/soil energy storage term. It is small compared to the other terms during the day, especially if roughness length is large (the turbulent heat fluxes being stronger). At night, this term is significant and is the same order of magnitude as $Q^{*}$. Also, $\Delta Q_{S}$ is mostly governed by the thermal characteristics of the vegetation and soil. The heat capacity of the soil is strongly influenced by the water content in it.

In addition to these impacts on the surface energy budget, one can note that the roughness also has an influence on the momentum fluxes and therefore on the profiles of wind, temperature, and humidity in the lowest tens of meters of the atmosphere.

In climate models, two complete datasets of surface parameters are widely used. The first one was derived by Wilson and Henderson-Sellers (1985), at a resolution of $1^{\circ}$, using lookup tables to derive parameters from 18 land cover types. The second one is from the International Satellite Land Surface Climatology Project (ISLSCP-2) initiative (at $0.25^{\circ}, 0.5^{\circ}$, or $1^{\circ}$ resolution). The ISLSCP-2 database encompasses satellite observations in the time period 1982-90 (more information available online at http://islscp2.gsfc.nasa.gov). Even though these two datasets are useful for classic global climate modeling, new needs have arisen for other applications. First, as regional climate modeling studies increase, the need for higher resolution is evident. The need is also obvious for NWP and mesoscale research models. Some actions were performed recently to increase the resolution for specific regions, for example, over Europe (Champeaux et al. 2000). Second, surface schemes evolve, representing more and more complex phenomena, and this evolution must be taken into account. In this respect, it is paramount to allow the initialization of surface schemes using the so-called tile approach (see, e.g., Avissar and Pielke 1989; Koster and Suarez 1992; Wetzel and Boone 1995), where a SVAT is run separately on different tiles (subgrid vegetation cover) within a given grid box. Surface fluxes are averaged with respect to the fractional coverage of each tile in the grid mesh. A typical tile decomposition is to compute separate energy budgets on bare soil, low vegetation, and woody vegetation parts (van den Hurk et al. 2000). Therefore, not just one but several values of a particular surface parameter (say LAI) are needed for each grid mesh.

The objective of this paper is to present a new global database, at a very high resolution $(1 \mathrm{~km})$, for use in atmospheric models at any scale, that follows the evolution of surface schemes; that is, allowing for both the tile and the classic aggregated approaches for the surface description.

This database is built using the following:

- A land cover map at a $1-\mathrm{km}$ resolution [built from a digital chart of the world (DCW) for the water mask, University of Maryland (UMD; Hansen et al. 2000) and the International Geosphere-Biosphere Programme Data and Information System (IGBP/DIS; Loveland et al. 2000) databases for vegetation over the globe, and Coordination of Information on the Environment (CORINE; Heymann et al. 1993) and Pan-European Land Cover Monitoring (PELCOM; Mucher et al. 2001) databases over Europe].

- A climate map [Koeppe and De Long (1958) over the globe and Forest Information from Remote Sensing (FIRS; European Commission 1995) over Europe].

- Normalized difference vegetation index (NDVI) inferred from 1-km observations of the Advanced Very High Resolution Radiometer (AVHRR) instrument on board the National Oceanic and Atmospheric Administration (NOAA) satellites.

- The Food and Agriculture Organization [(FAO) 1988] database at $10-\mathrm{km}$ resolution for soil texture.

Section 2 details the different steps of the method that resulted in an ecosystem classification map using these land cover and climate maps together with time series of the NDVI. Section 3 details how a set of surface parameters was assigned to each pixel of the classification map based on lookup tables. Validation of this dataset against in situ data and comparison to other remote sensing data is carried out in section 4. Finally, section 5 presents the application of this new dataset in the ARPEGE climate model (Déqué et al. 1994).

\section{Derivation of an ecosystem map}

a. Overview of the method

The large variability of the vegetation does not permit a straightforward derivation of the land surface parameters based uniquely on a general land surface inventory (Brown et al. 1993). For instance, for vegetation sharing the same nomenclature but located under different climates, different behavior of the vegetation may, however, be obtained. In this regard, the forests of northern Europe and the Mediterranean basin yield a typical illustration. This can also occur for the case of crops that present a time shift in their seasonal physiological status. To avoid any misinterpretation, it is mandatory to first stratify the landscape into homogeneous zones (Loveland et al. 2000; Mucher et al. 2001). The goal here is to segregate areas of the same land cover type into such homogeneous zones using climate information.

\section{b. Derivation of the land cover map}

The production of a land cover map was achieved by gathering various sources of data. The coastlines, lakes, 
and rivers are delineated from the information content of the DCW data at a $1-\mathrm{km}$ resolution. The DCW was digitized under contract of the U.S. Defense Mapping Agency (DMA).

Two global land cover datasets were available at 1$\mathrm{km}$ resolution: the IGBP/DIS (Loveland and Belward 1997; Loveland et al. 2000) and the University of Maryland database (Hansen et al. 2000), which are both derived from the 1992-93 AVHRR dataset (Eidenshink and Faudeen 1994). These two land cover maps have notable differences (Hansen et al. 2000). The mosaic class in the IGBP/DIS product, which is a merging of natural vegetation and cropland, is not very convenient for our purpose. In this study, the designation of the cover types is essentially derived from the UMD global land cover map. However, the permanent snow occupation and wetland bodies are based on the IGBP/DIS database. Such information is used at $1-\mathrm{km}$ resolution. Actually, 15 land surface types are referenced (see Fig. $1)$. They are evergreen needleleaf forest, evergreen broadleaf forest, deciduous needleleaf forest, deciduous broadleaf forest, mixed forest, woodland, wooded grassland, closed shrubland, open shrubland, grassland, cropland, bare soil, urbanized areas, permanent snow and ice, and wetlands.

Over the European continent, the cover types from the CORINE land cover classification are preferred. They are at a 250-m resolution (Heymann et al. 1993; our Fig. 2) and are degraded to a $1-\mathrm{km}$ resolution for the purpose of our study. The CORINE land cover database is made by visual interpretation of high-resolution satellite images, for example, Landsat Thematic Mapper and Spot XS scanner images, at a scale of 1: 100 000, with simultaneous consultation of ancillary data. At present, the CORINE land cover database is the most detailed land cover database that covers a large part of Europe. Forty-four land cover categories are represented, notably encompassing 11 urban types, 5 water types, 3 major forest types (broadleaf, needleleaf, and mixed), and a cropland class. The characteristics of the crop, such as its vegetative cycle, are not detailed. The role of the UMD land cover map is to compensate for the lack of CORINE data in certain areas, except over Scandinavia where the PELCOM database information (Mucher et al. 2001) was preferred.

\section{c. Derivation of the climate map}

The use of a climatologically based classification represents crucial additional information to discriminate two areas of vegetation that are from the same land cover class but that belong to different geographic domains, and, hence, evolve differently in response to different environmental factors. For instance, an open shrubland can represent tundra in polar regions and a savannah in tropical areas, and it is clear these two vegetation canopies behave differently. The shrubland is a typical example, which can be found in other parts of the world.
The map of the terrestrial climates considered herein is based on the work of Koeppe and De Long (1958). Actually, 16 climates were identified: dry summer subtropical, tropical desert, semiarid tropical, wet and dry tropical, wet equatorial, trade wind littoral, humid subtropical, semiarid continental, intermediate desert, moderate polar, cool marine, polar, cool littoral, humid continental, extreme subpolar, and marine subpolar. Similar to the land cover strategy, the resolution of the climate map was increased over Europe owing to the investigations of the FIRS project [European Commission (EC) 1995]. Europe has been divided into regions based on geofactors, such as climate, soil, and topography. Figure 3 exhibits the global composite climate map.

\section{d. NDVI datasets}

Remotely sensed data can provide useful information at the appropriate temporal and spatial scales. Most widely used satellite information relies on the full resolution maps of the vegetation index NDVI derived from the AVHRR visible and near-infrared spectral bands. For the sake of this study, data covering an annual cycle were used: the IGBP 1-km AVHRR monthly NDVI composites, corresponding to the range period of April 1992-March 1993 (the only one available at the global scale at such a fine resolution), and the monthly NDVI composites created by the Deutsches Zentrum für Luftund Raumfahrt (DLR), corresponding to the year 1997, for Europe (Mucher et al. 2001). The processing steps of the IGBP dataset have been described by Eidenshink and Faundeen (1994).

It is worth emphasizing that no major atmospheric anomaly, such as an El Niño event, occurred within the period 1992-93. The impact of such phenomena is to change the location of regions of convective systems, thereby leading to severe rainfall or drought anomalies, and therefore vegetation development anomalies. A strong El Niño (or La Niña) could have biased such a study. The Pinatubo eruption of June 1991, notably increased the aerosol concentration in the stratosphere during the second half of 1991. However, the NDVI anomaly plotted between 1981 and 1995 does not show a strong deviation during the period 1992-93 (Buermann et al. 2002). The impact of the extreme solar zenith angle due to an orbital drift of the NOAA satellite had a dramatic effect on the measured NDVI, but only in the latter part of 1993 and for most of 1994 (Gutman 1999). Furthermore, in Europe, no important climatic anomalies were detected during the year 1997.

Despite the above limitations, no major climatic anomalies were detected at global scale; so, even if the more arid ecosystems (as some grassland or shrublands) would still be expected to vary from year to year, these data can be considered as representative of the vegetation for a normal year. 

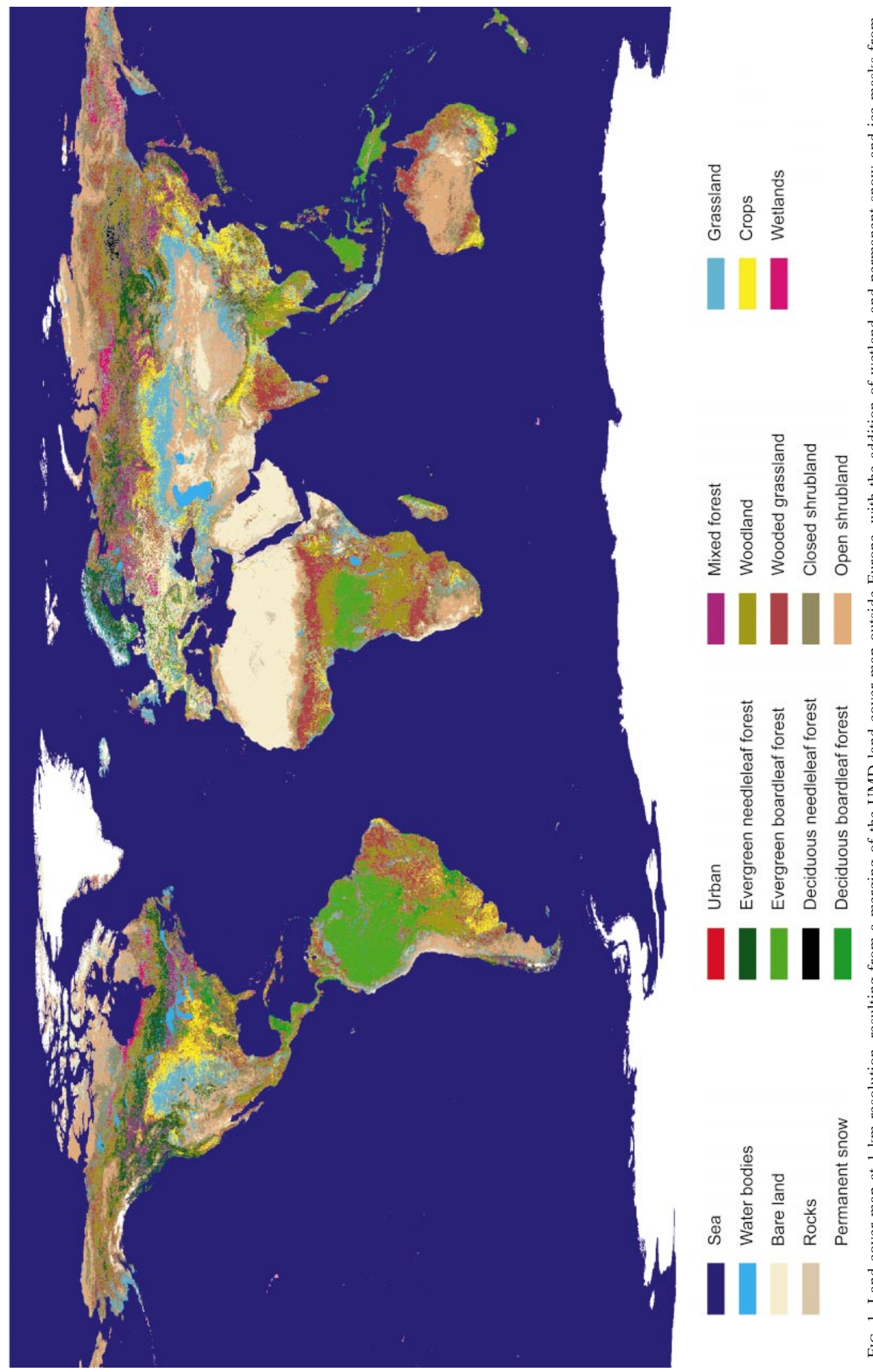

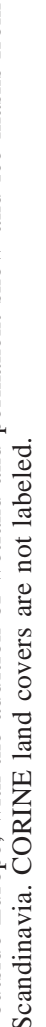

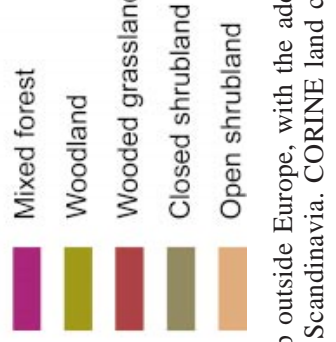

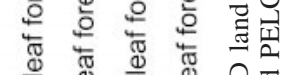

$$
\begin{aligned}
& \text { ष }
\end{aligned}
$$

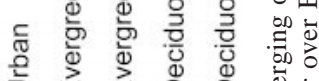

$$
\begin{aligned}
& \text { IIIIII }
\end{aligned}
$$

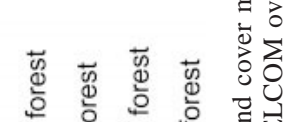

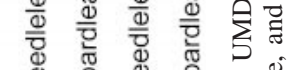$$
\text { ष्ष }
$$

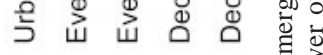



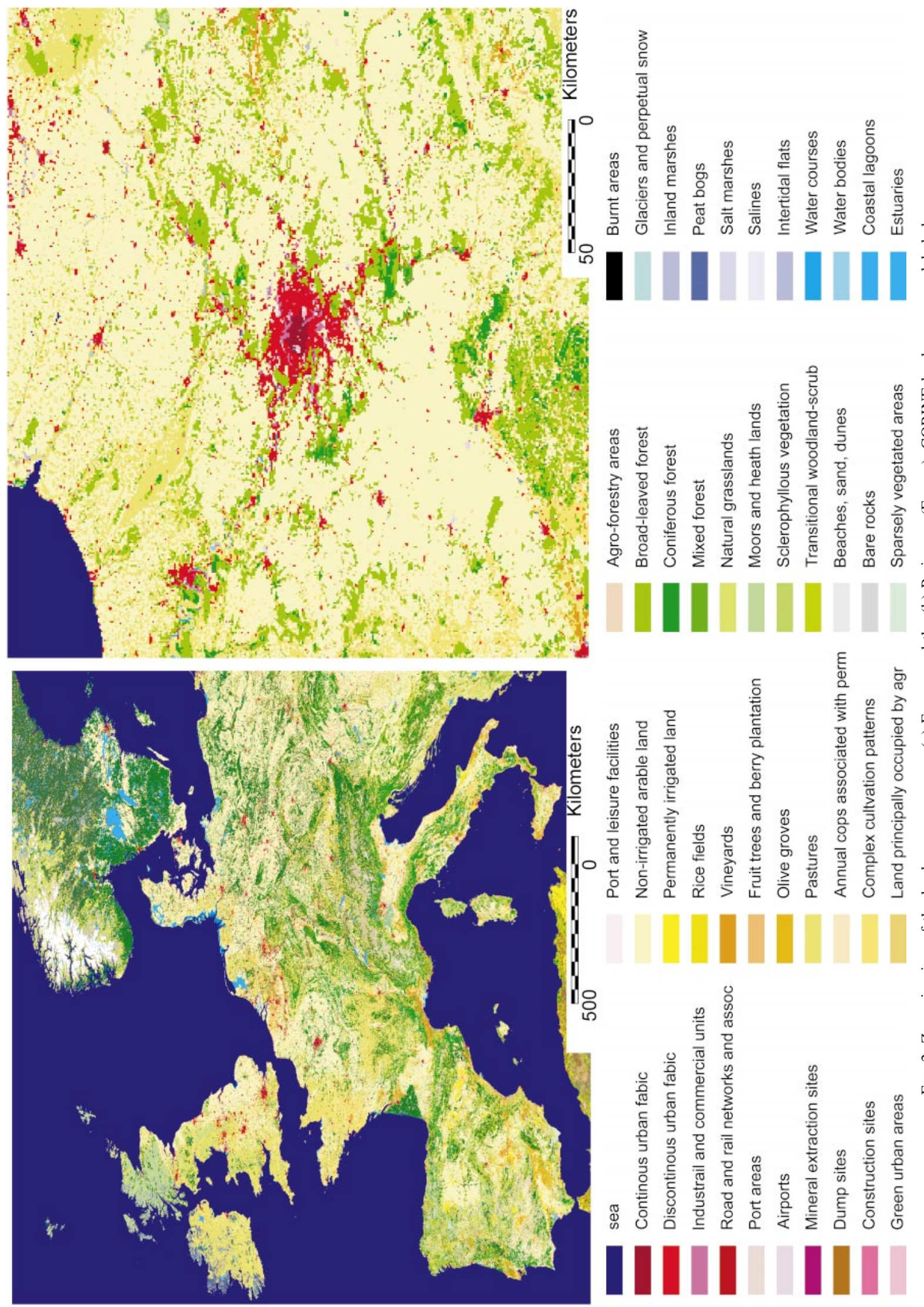

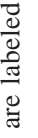
(n) 

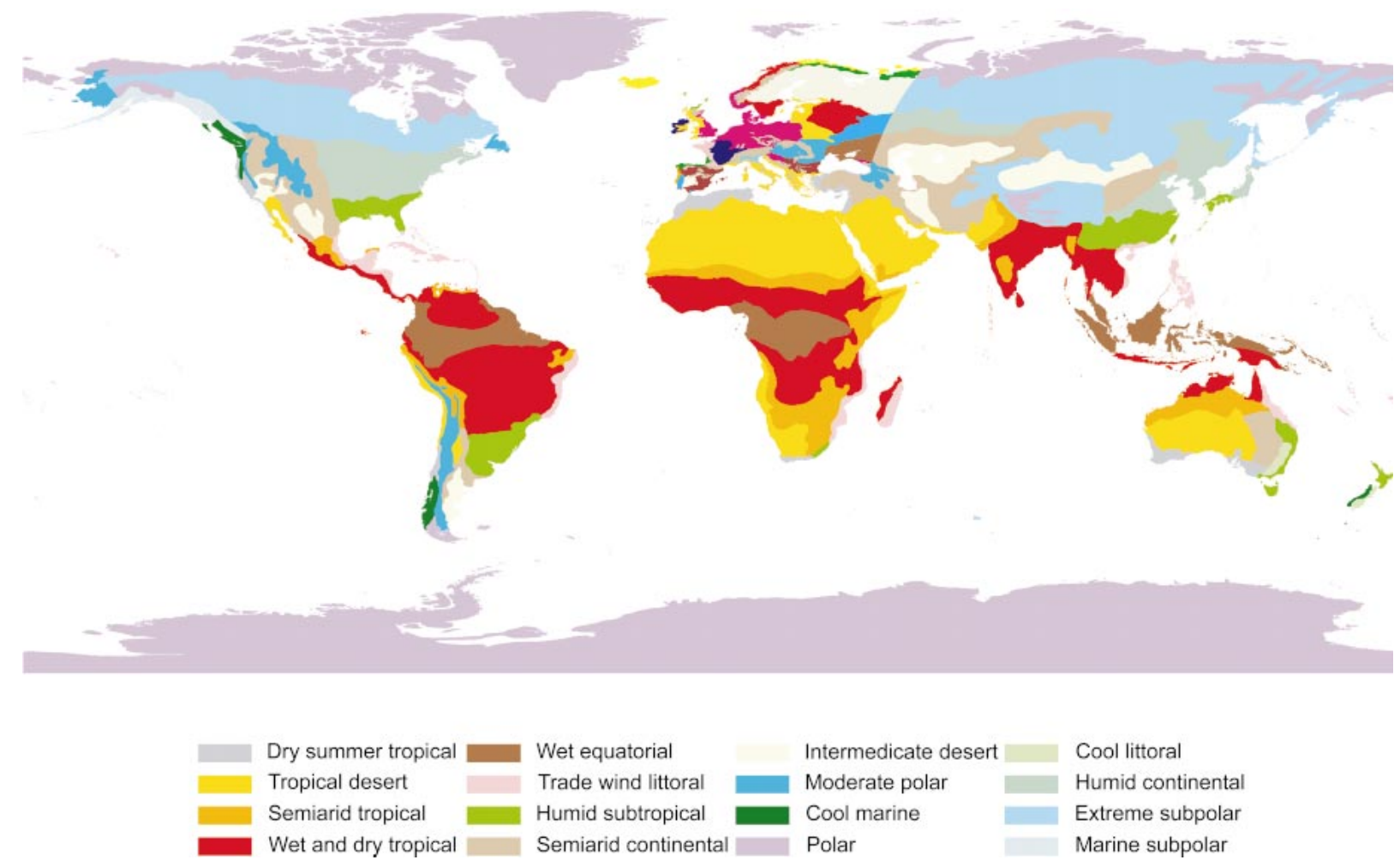

FIG. 3. Climate map from Koeppe and De Lond (1958) outside Europe, and the FIRS project climate map over Europe. Climates of FIRS are not labeled.

\section{e. Merging land-use and climatic information}

The combination of the 15 cover types with the 16 climates for the 5 continents has led to a large number of ecosystems. Some of them fill in a very small area and are no longer representative. Interestingly, others belonging to different climates or continents show a similar trend. The NDVI profiles are averaged for each ecosystem (defined by its land cover, climate, continent, and hemisphere). Then, the selection of representative ecosystems relies on the analysis of the temporal profile of the monthly NDVI products. The fusion of different ecosystems into one was performed according to the following rules.

1) Two merged ecosystems must share the same land cover types as cited above. An exception to this is that some forests could be fused, especially when one is much less representative than the other. It is then referred to as a pure forest, given the name of the dominant species (needleleaf or broadleaf, evergreen or deciduous) or as a mixed forest.

2) The merging was performed by comparing the NDVI annual profiles (peak values, temporal trends). If two profiles have their extreme values separated by at least a month, they are perceived as being representative of different vegetation and are not merged.

3) Ecosystems in the humid equatorial climate are assumed to be identical on both sides of the equator.
4) Two ecosystems corresponding to the same cover type but located on different continents could be merged.

In the following, for sake of simplicity, the term "ecosystem" will stand for "representative ecosystem."

\section{f. Overview of the new classification}

The final procedure leads to 125 major terrestrial ecosystems over the globe, with the exception of Europe. Each of them represents a vegetation entity, which promotes a possible assignment of parameter sets. For example, the various ecosystems issued from the UMD nomenclature woodland and crop classes are displayed in Figs. 4a and 4b. Based on NDVI and climate information, splitting those land covers into 17 categories for the woodland and 30 categories for the cropland is allowed.

Over the European continent, the differentiation of 90 ecosystems is required. Most of them arise from splitting the nonirrigated cropland cover, the grassland type, and the three forest types initially in the CORINE dataset.

The differentiation of all these ecosystems allows a better estimation of the evolution of each of the vegetation parameters (minimum and maximum LAI, its annual variation, or the evolution of roughness and vegetation fractional cover). 

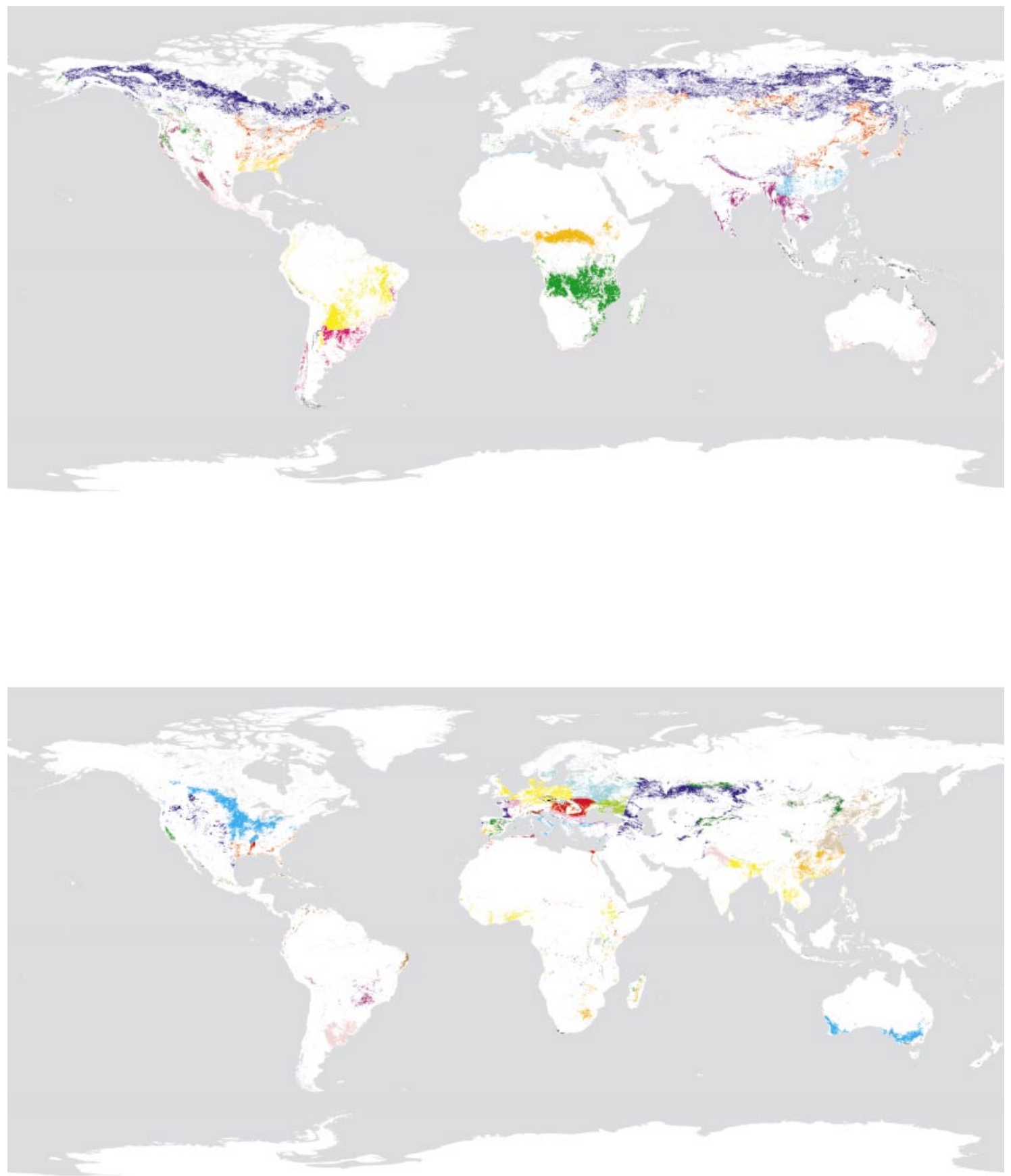

FIG. 4. Representative homogeneous ecosystems derived from (top) the woodland land cover and (bottom) the crop land cover. In each panel, a specific color corresponds to one ecosytem.

\section{Derivation of surface parameters}

SVAT scheme parameters (such as vegetation parameters) must be derived from the 215 ecosystems to provide consistent datasets that can be used in meteorological models. In addition, the soil texture, merely based on the percentages of clay and sand, is taken from the FAO data (at 10-km resolution; FAO 1988).

\section{a. Composition of the land ecosystems}

The first necessary information that is used to conveniently assign the surface parameters is a basic distinction of the landscape units. They are the sea, the inland water bodies, the human-built surfaces, and the land (vegetation or soil). Knowledge of the proportion of the corresponding surface spatial extensions is clearly 
TABLE 1. Fractions of woody vegetation, herbaceous vegetation, and bare soil for each land cover. The variations of fractions inside a land cover depend on climate.

\begin{tabular}{|c|c|c|c|}
\hline & $\begin{array}{c}\text { Bare soil: } \\
\text { Bare soil/rocks/permanent } \\
\text { snow }\end{array}$ & $\begin{array}{c}\text { Woody vegetation: } \\
\text { Evergreen broadleaf/ } \\
\text { deciduous broadleaf/ } \\
\text { needleleaf }\end{array}$ & $\begin{array}{c}\text { Herbaceous: } \\
\text { C3/C4/irrigated } \\
\text { crops/natural } \\
\text { herbaceous (temperate)/ } \\
\text { natural herbaceous (Tropics)/ } \\
\text { wetland and irrigated } \\
\text { herbaceous }\end{array}$ \\
\hline Any forest & & $100 \%$ & \\
\hline Woodland & $0 \%-10 \%$ & $40 \%-50 \%$ & $50 \%$ \\
\hline Wooded grassland & $0 \%-20 \%$ & $20 \%-30 \%$ & $50 \%-70 \%$ \\
\hline Closed shrubland & $20 \%-30 \%$ & $20 \%$ & $50 \%-60 \%$ \\
\hline Open shrubland & $20 \%-60 \%$ & & $40 \%-80 \%$ \\
\hline Grassland & & & $100 \%$ \\
\hline Crops & & & $100 \%$ \\
\hline $\begin{array}{l}\text { Bare soil; rock, } \\
\text { permanent snow }\end{array}$ & $90 \%-100 \%$ & & $0 \%-10 \%$ \\
\hline
\end{tabular}

of primarily importance in atmospheric modeling for the use of different surface schemes. Note that some ecosystems in reality can be a mixture of these surfaces, such as for wetlands (land and inland water) and suburban areas (land and artificial surfaces).

Over the urban areas, the surface parameters solely include the impervious surfaces. A single urban cover type is considered in the UMD data, and urban parameters are estimated for typical North American suburban areas. In Europe, the city parameters are more realistic owing to the special attention paid to the urban areas in the CORINE land cover database. In particular, surface parameters are prescribed for the city centers, the suburban areas, and the commercial or industrial areas, and even for some remaining urban covers. The surface parameters are from the Town Energy Balance (TEB) scheme (Masson 2000; Masson et al. 2002).

Over natural areas, the problem of correctly allocating the surface parameters is much more complex due to the high variability and diversity of the vegetation types. Each ecosystem is truncated into the fractions of woody vegetation, herbaceous vegetation, and bare soil. In fact, a subdivision is necessary for further parameter assignment (see section 3c). This leads to 12 vegetation types in 3 categories: (i) bare soil, rocks, permanent snow and ice; (ii) C3 crops, C4 crops, irrigated crops, natural herbaceous (temperate), natural herbaceous (Tropics), wetland herbaceous or irrigated grass; (iii) needleleaf trees, evergreen broadleaf trees, and deciduous broadleaf trees. Most of the 215 ecosystems are composed of only one of these 12 vegetation types (so-called pure ecosystems). Over Europe, almost all of the ecosystems are pure. However, some land covers in the UMD classification ("woodland," "wooded grassland," "closed shrubland," "open shrubland") are composite, and lead to "mixed" ecosystems.

Table 1 shows the relationship between the initial land cover of an ecosystem and its composition with respect to these vegetation types. Note the existence of small variations for the same initial land cover and the derived coverage fractions. These variations are a function of climate. The fraction of each type (one type of woody vegetation, one type of herbaceous, and bare soil) was set in agreement with recent studies (Defries et al. 2000; Hansen et al. 2000). Hence, an ecosystem coming from the "grassland" land cover is assumed pure, namely, composed of natural herbaceous vegetation; while a woodland ecosystem is considered mixed, namely, formed of herbaceous and forest types. For crops, the C3 type is omnipresent except in the tropical and equatorial belts, and where corn is intensively cultivated. The C4 crops category is applied in such situations.

\section{b. Vegetation types, tiles, and aggregation scheme of the parameters}

As stated before, the database must allow for both the surface "tile" and the classic aggregated approaches. A derivation of the surface parameters is then needed for each vegetation type of each of the 215 ecosystems. However, in the classic case (only one SVAT run per grid point), as is the case for most applications, a parameter aggregation procedure is carried out (following Noilhan and Lacarrère 1995; Mahfouf et al. 1995; see Fig. 5a). For sake of coherence, exactly the same procedure is used for aggregation at a coarser resolution (Fig. 5b). The prescription of the various parameters is the objective of the remaining subsections.

\section{c. Leaf area index (LAI)}

The LAI is defined as the surface area of leaves contained in a vertical column normalized by its crosssectional area. It has been addressed as a crucial parameter of SVAT models since it determines the plant transpiration. It is important to consider not only its seasonal variation, but also its regionalism according to climates, because of the vegetation dynamics.

The effort of merging, described in section 2, permitted the construction of homogeneous ecosystems. 
a) Example: aggregated parameters for: 1 pixel of mixed ecosystem, (say a woodland)

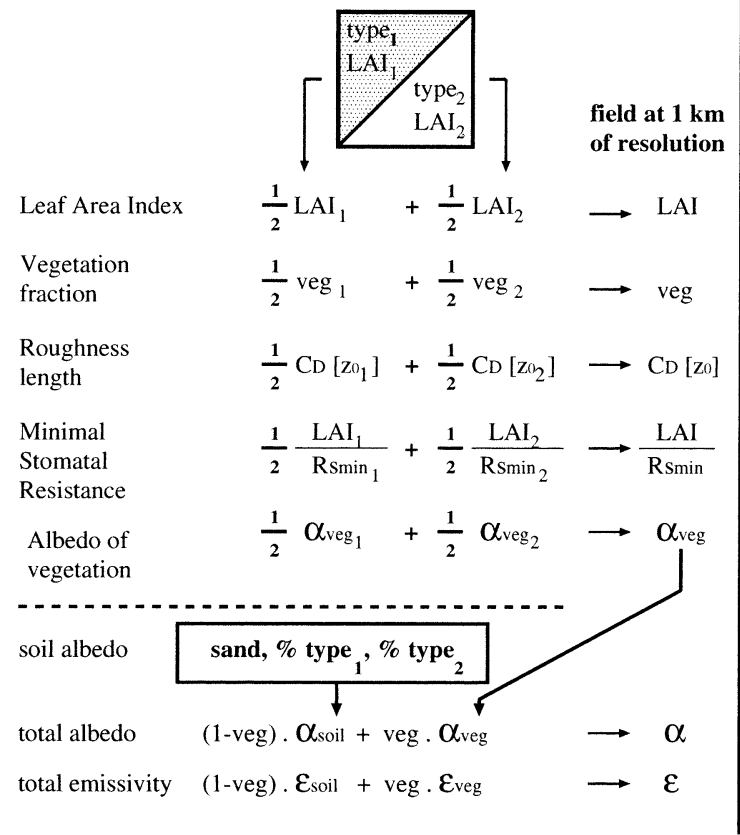

b) Example: aggregation of 4 pixels:

1 pixel of pure ecosystem " 1 " (say a forest),

2 pixels of pure ecosystem "2" (say crops),

1 pixel of mixed ecosystem "3", (say a woodland)

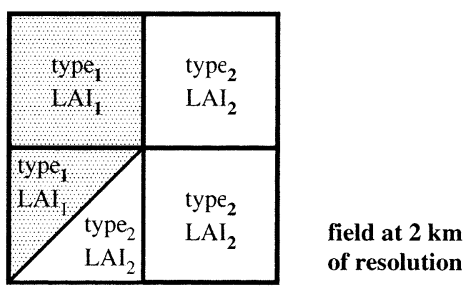

Leaf Area Index

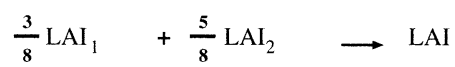

Vegetation

fraction

$\frac{3}{8} \operatorname{veg}_{1}+\frac{5}{8} \operatorname{veg}_{2} \longrightarrow$ veg

Roughness

length

$\frac{3}{8} \mathrm{CD}\left[\mathrm{zo}_{1}\right]+\frac{5}{8} \mathrm{CD}\left[\mathrm{Zn}_{2}\right] \rightarrow \mathrm{CD}\left[\mathrm{zo}_{0}\right]$

Minimal

Stomatal

Resistance

Albedo of

vegetation

-

soil albedo

total albedo

total emissivity $\frac{3}{8} \frac{\mathrm{LAI}_{1}}{\mathrm{Rsmin}_{1}}+\frac{5}{8} \frac{\mathrm{LAI}_{2}}{\mathrm{Rsmin}_{2}} \rightarrow \frac{\mathrm{LAI}}{\mathrm{Rsmin}}$

$\frac{3}{8} \alpha_{v g_{1}}+\frac{5}{8} \alpha_{v g_{2}} \longrightarrow \alpha_{v e g}$

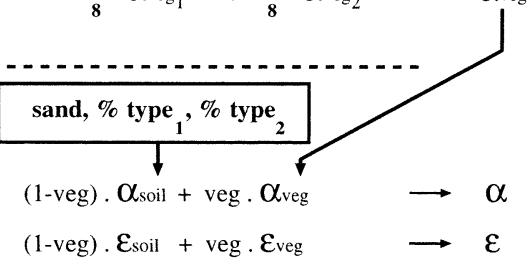

FIG. 5. Aggregation rules used to derive surface parameters: (a) aggregation of the surface characteristics of a mixed ecosystem pixel, and (b) aggregation toward a coarser resolution of the surface characteristics of several pixels, whether they are mixed or not. Here $C_{D}$ is the neutral drag coefficient at $10 \mathrm{~m}$, equal to $\kappa^{2} / \mathrm{ln}^{2}\left(10 / z_{0}\right)$, where $\kappa$ is the von Karman constant and $z_{0}$ is in meters. The Veg $, \mathrm{Rs}_{\min 1}, z_{01}$, $\alpha_{1}\left(\operatorname{Veg}_{2}, R s_{\min 2}, z_{02}, \alpha_{2}\right)$ are estimated from $\mathrm{LAI}_{1}\left(\mathrm{LAI}_{2}\right)$ and the vegetation type 1 (2) according to Table 2.

Because of this, the actual variability of the vegetation parameters within each ecosystem can be reasonably assumed to be weak spatially, even if it is large temporally. From this, it is legitimate to derive a set of biophysical properties per ecosystem. A number of studies have demonstrated the close relationship between the LAI and NDVI (Asrar et al. 1984; Baret and Guyot 1991). ISLSCP LAIs are computed using relations between the LAI, the fraction of photosynthetically active radiation (FPAR), and NDVI (Sellers et al. 1994), while the Polarization and Directionality of the Earth's Reflectance (POLDER) and the Moderate Resolution Imaging Spectroradiometer (MODIS) based LAIs are deduced from NDVI values using surface radiative schemes (Roujean and Lacaze 2002; Lacaze et al. 2001; Knyazikhin et al. 1998). Here, contrary to these three datasets, the LAI is not computed for each pixel, but instead it is estimated for a whole ecosystem. The method is much more simple, but robust. In particular, the LAI values vary between realistic limits prescribed for each ecosystem. The LAI is obtained according to the following rules.

\section{1) Pure ecosystems}

Each pure ecosystem includes a single vegetation type with a corresponding LAI. Note that the understory LAI is incorporated for the forests. Due to the lack of a unique relationship between LAI and NDVI, this NDVI information serves to make a dynamic adaptation of the LAI from the minimum and maximum values found in the literature:

$$
\begin{aligned}
\mathrm{LAI}= & \mathrm{LAI}_{\text {min }} \\
& +\left(\mathrm{LAI}_{\max }-\mathrm{LAI}_{\text {min }}\right) \frac{\mathrm{NDVI}-\mathrm{NDVI}_{\text {min }}}{\mathrm{NDVI}_{\text {max }}-\mathrm{NDVI}_{\text {min }}} .
\end{aligned}
$$

\section{2) Mixed ecosystems}

Each mixed ecosystem can include one herbaceous vegetation type and/or one woody vegetation type. Therefore, LAI must be defined for both of them. Two following cases must be distinguished. 
1) Over North America, eastern Europe, central Russia, and Southeast Asia, the woodland and wooded grassland UMD land covers represent transitions between crops and forest. Then the LAI of the dominant crop (forest) ecosystem in the area is assigned to the herbaceous (woody) vegetation type of the mixed ecosystem.

2) For a landscape composed of trees and natural herbaceous vegetation, and possibly bare soil, like from equatorial forests to tropical deserts and from boreal forests to tundra, a procedure similar to the pure ecosystems is applied for each type of the mixed ecosystem. The LAI time profile is then given by the NDVI time profile. This holds for all vegetation types of the ecosystem.

The (aggregated) LAI maps at $1-\mathrm{km}$ resolution derived using these rules are plotted in Figs. 6a (January) and $7 \mathrm{a}$ (June). Comparisons with ISLSCP2 and POLDER datasets are described in section $4 b$.

\section{d. Other vegetation parameters}

SVATs commonly use additional surface parameters, such as the vegetation fraction (the fractional area on the ground that is occupied by vegetation), the roughness length, the minimal stomatal resistance (that plays a role in the transpiration of plants), albedo, and emissivity. Rooting depth used in surface models generally depends more on vegetation types than on the soil type (Calvet et al. 1997; Delire et al. 1997). The total soil depth is also related to the vegetation type based on the aforementioned works. Thus, they are initialized in this new dataset for each ecosystem, independently of the soil properties. All of these parameters, computed in a coherent manner for each vegetation type, are presented in Table 2.

\section{1) WoOdy VEgETATION AND FORESTS}

Due to the constant height of the trees on an annual basis, the roughness length is assumed constant for the woody vegetation in each ecosystem. It is computed from a typical tree height $(h)$, ranging from $30 \mathrm{~m}$ for equatorial forests to $15 \mathrm{~m}$ for temperate forests and 2 $\mathrm{m}$ for bushes, the latter to be consistent with the definition of the UMD closed shrubland cover. The vegetation fraction is assumed to remain near unity for forests all year along, in considering both green and senescent material. In summer, green leaves evidently cover most of the surface, and in winter for deciduous trees, they are replaced by dead leaves over the ground and eventually moss. Root depth of trees is assumed to range from $8 \mathrm{~m}$ in equatorial forests (Canadell et al. 1996; Delire et al. 1997) to $2 \mathrm{~m}$ for bush trees and temperate and boreal forests (Canadell et al. 1996). Albedo differs following the woody vegetation type. For coniferous trees, a vegetation albedo of 0.10 is retained as a good estimate of both boreal (Betts and Ball 1997) and temperate (Gash et al. 1989) coniferous forests. It is approximately 0.13 for the equatorial forests (Shuttleworth et al. 1984; Culf et al. 1995, 1996; Wright et al. 1996), and 0.15 for deciduous broadleaf trees (Betts and Ball 1997). Minimal stomatal resistance $\left(\mathrm{Rs}_{\min }\right)$ is well documented for equatorial forests, leading to a value of 250 $\mathrm{s} \mathrm{m}^{-1}$ (Delire et al. 1997), but it is less for other forests. A value of $150 \mathrm{~s} \mathrm{~m}^{-1}$ is set, in accordance with Hydrological Atmospheric Pilot Experiment-Modelisation du Bilan Hydrique (HAPEX-MOBILHY) field measurements in the Landes (France) coniferous forest (Bougeault et al. 1991; Noilhan et al. 1991).

\section{2) NAtural herbaceOus tyPES, GRASSLANDS}

As for the forests, the vegetation fraction does not vary with time, as vegetation stands where it is, even if dryed (in dry summer climates) or dead in winter (in colder climates). However, contrary to trees, the height of herbaceous vegetation varies with time, depending on its phenomenological state. Therefore, we related the height of this vegetation to the LAI, $h=\mathrm{LAI} / 6$, as used in Calvet et al. (1998). Root depth is generally set to $1.5 \mathrm{~m}$ (Canadell et al. 1996), and the total soil depth is $0.5 \mathrm{~m}$ deeper. The vegetation albedo for herbaceous vegetation is set to 0.20 (Shuttleworth et al. 1984; Culf et al. 1995, 1996; Grant et al. 2000). The $\mathrm{Rs}_{\min }$ is much lower for herbaceous vegetation than for woody vegetation (approximately $40 \mathrm{~s} \mathrm{~m}^{-1}$; Noilhan and Planton 1989; Jacquemin and Noilhan 1990), except in the Tropics, where values are larger (Delire et al. 1997; Dorman and Sellers 1989; Douglas 2001; Pitman et al. 1999; Zhao and Pitman 2000). A value of $120 \mathrm{~s} \mathrm{~m}^{-1}$ is preferred there.

\section{3) CRops}

Cultivated lanscapes evolve very differently from the unmanaged ones. Because of ploughing, bare soil is directly in contact with the atmosphere once the crop is harvested. Therefore, the vegetation fraction is far from being constant, even varying from near zero after plowing, to almost one when crop is fully developed. Therefore, for crops, the vegetation fraction is related to the LAI (after Kanemasu et al. 1977), which gives the seasonal variability. As for natural herbaceous vegetation, roughness length is related to LAI, with an exponential form, and has a height of $1 \mathrm{~m}$ before maturity (for a LAI of 3.5; J.-C. Calvet 2001, personal communication). Rooting depth, soil depths, $\mathrm{Rs}_{\min }$, and vegetation albedo $(0.20)$ are similar to the natural herbaceous ones.

\section{4) Mixed ecosystems}

As explained in section $3 b$, the surface parameters are evaluated for each vegetation type present in the 

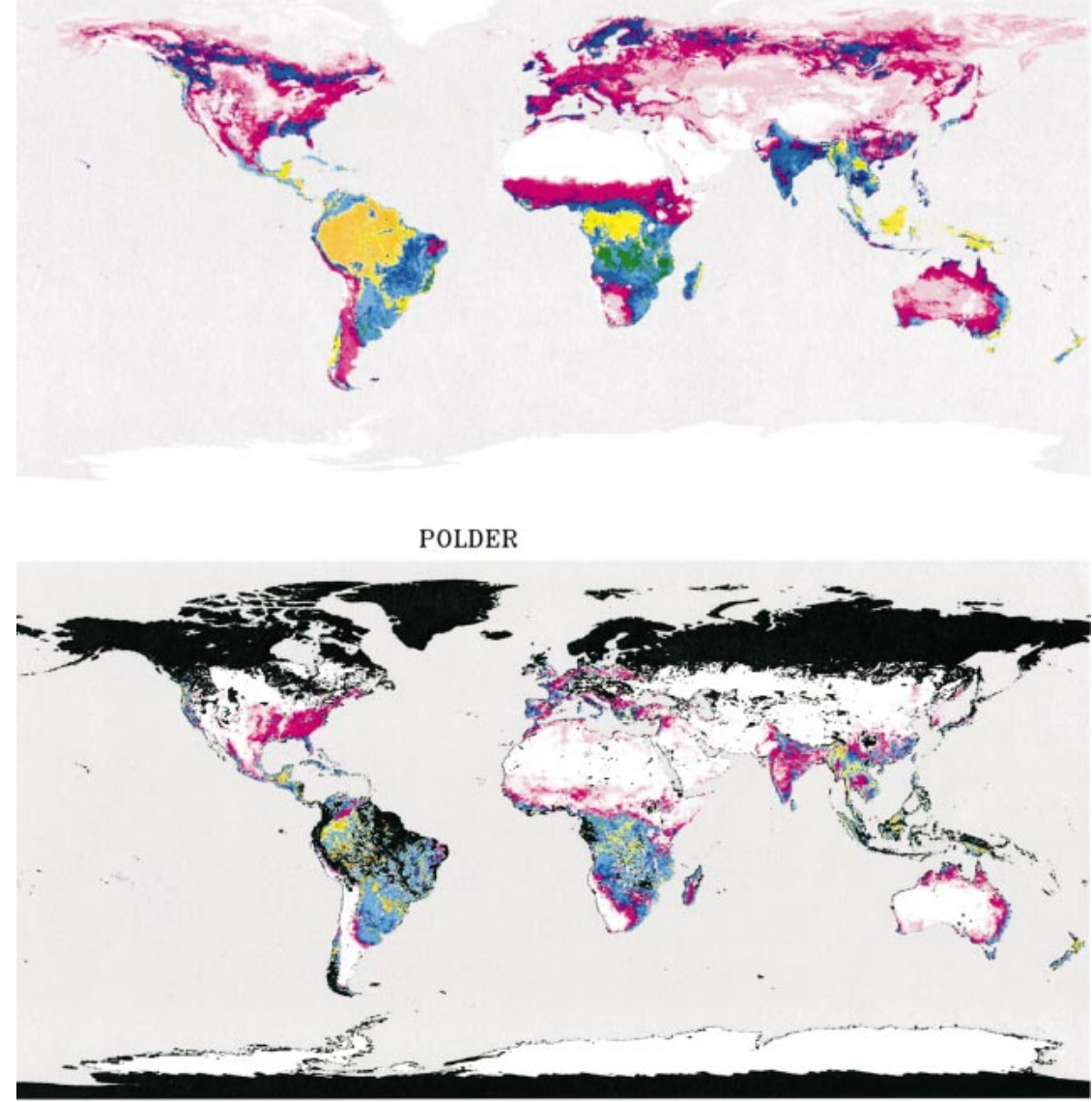

ISLSCP2

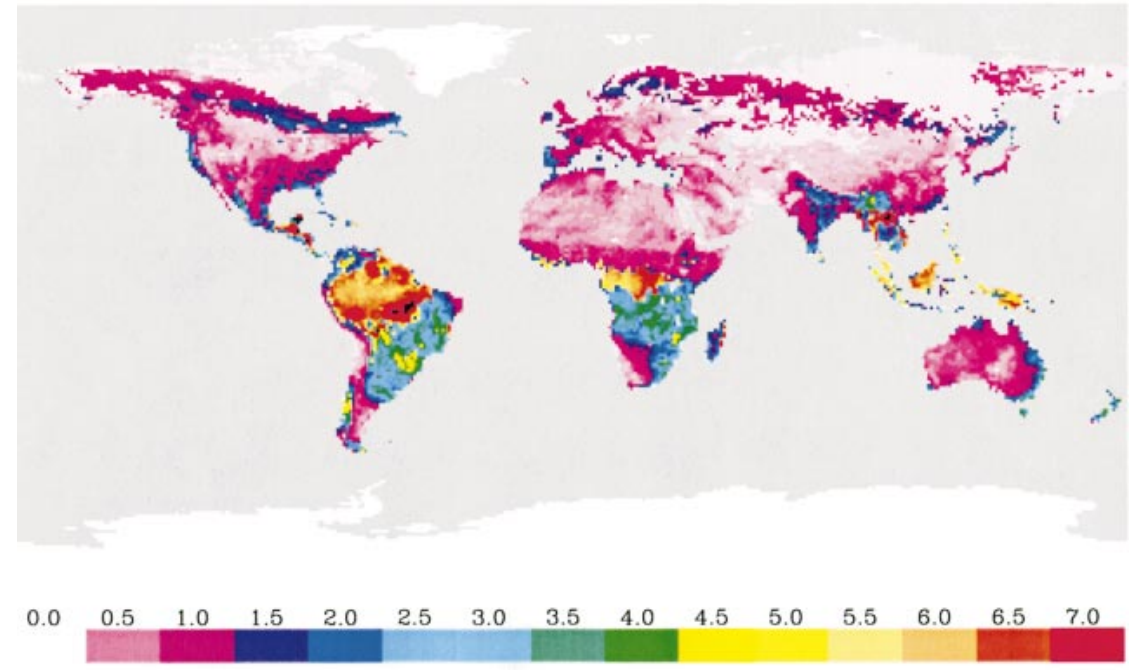

FIG. 6. LAI for Jan from (a) this study, (b) POLDER (Roujean and Lacaze 2002), and (c) the 1982-90 average of the ISLSCP-2 data. 

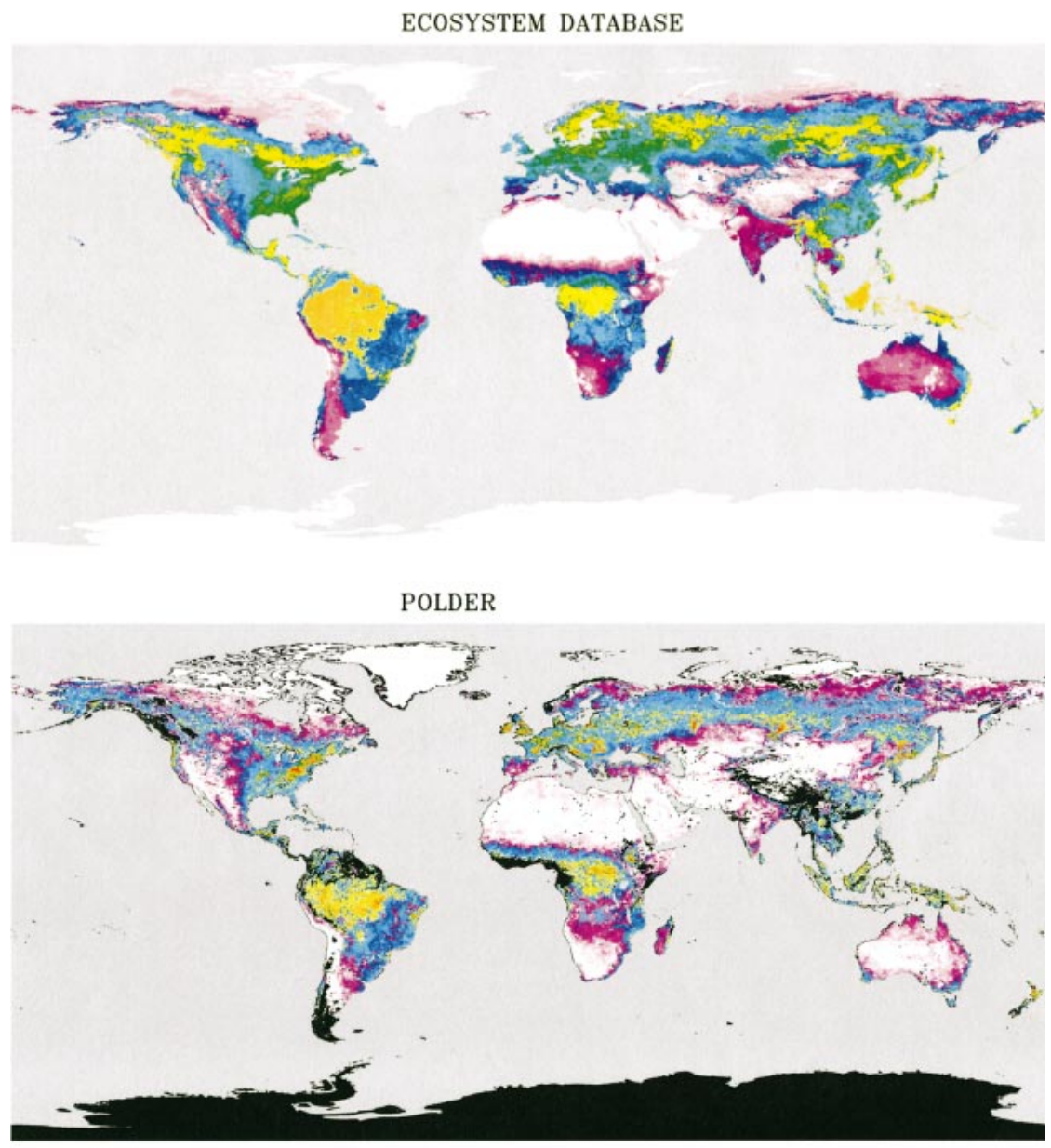

ISLSCP2

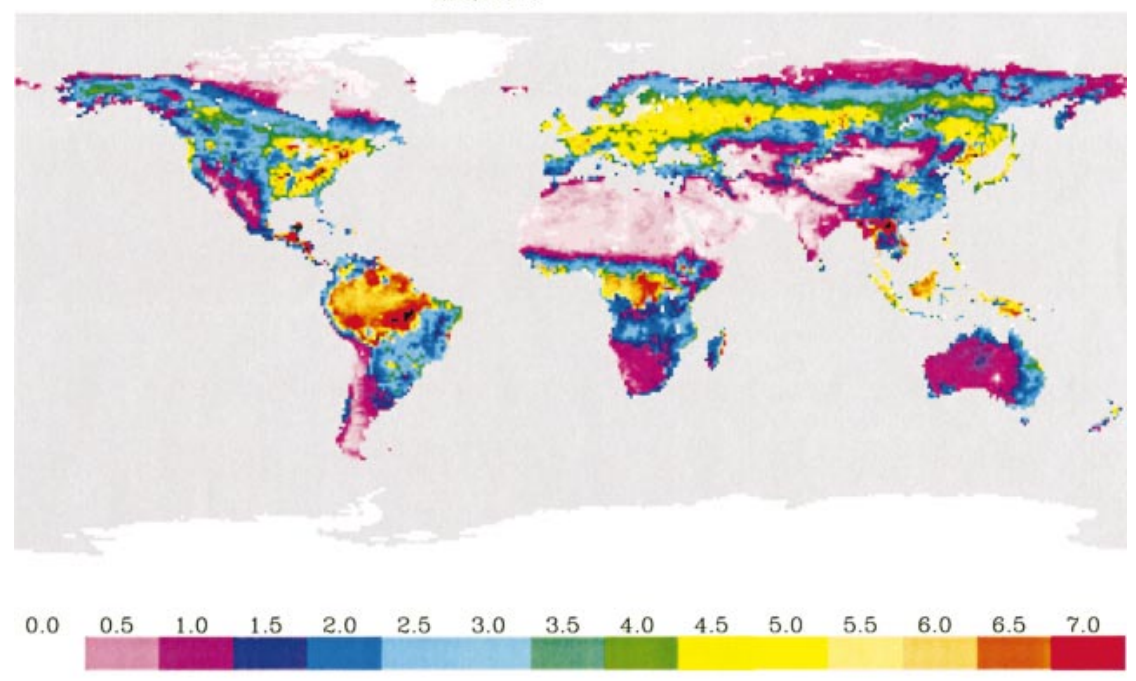

FIG. 7. Same as Fig. 6, but for Jun. 
TABLE 2. Formulations of surface parameters for this database.

\begin{tabular}{|c|c|c|c|c|c|}
\hline $\begin{array}{l}\text { Vegetation } \\
\text { type }\end{array}$ & $\begin{array}{c}\text { Total } \\
\text { vegetation } \\
\text { fraction }\end{array}$ & $\begin{array}{l}\text { Roughness } \\
\text { length } \\
\text { (m) }\end{array}$ & $\begin{array}{c}\text { Albedo } \\
\text { of } \\
\text { vegetation }\end{array}$ & $\begin{array}{l}\text { Minimal } \\
\text { stomatal } \\
\text { resistance } \\
\left(\mathrm{s} \mathrm{m}^{-1}\right)\end{array}$ & $\begin{array}{c}\text { Emissivity } \\
\text { of } \\
\text { vegetation }\end{array}$ \\
\hline Bare soil & 0 & 0.013 & & & \\
\hline Rocks & 0 & 0.13 & & & \\
\hline Permanent snow and ice & 0 & 0.0013 & & & \\
\hline C3 crops & $1-e^{-0.6 \mathrm{LAI}}$ & $0.13 \min \left[1, e^{(\mathrm{LAI}-3.5) / 1.3}\right]$ & 0.20 & 40 & 0.97 \\
\hline $\mathrm{C} 4$ and irrigated crops & $1-e^{-0.6 \mathrm{LAI}}$ & $0.13 \min \left[2.5, e^{(\mathrm{LAI}-3.5) / 1.3}\right]$ & 0.20 & 120 & 0.97 \\
\hline Natural herbaceous (Tropics) & 0.95 & $0.13^{\mathrm{LAI} / 6}$ & 0.20 & 120 & 0.97 \\
\hline Other herbaceous & 0.95 & $0.13^{\mathrm{LAI} / 6}$ & 0.20 & 40 & 0.97 \\
\hline Needleleaf trees & 0.95 & $0.13 h$ & 0.10 & 150 & 0.97 \\
\hline Evergreen broadleaf trees & 0.99 & $0.13 h$ & 0.13 & 250 & 0.97 \\
\hline Deciduous broadleaf trees & 0.95 & $0.13 h$ & 0.15 & 150 & 0.97 \\
\hline
\end{tabular}

mixed ecosystem (the relevant woody vegetation parameters for the woody vegetation part of the ecosystem, and the relevant natural herbaceous or crop parameters for the herbaceous part). Aggregation to obtain only one parameter is eventually performed according to Fig. 5.

\section{e. Bare soil and total albedo and emissivity}

The determination of the albedo and emissivity products at a large scale can be realized by following two different approaches. The first one is the direct extraction from the satellite measurement based on the inversion of the reflectance models. This presents the advantage of having directly concomitant spatially distributed radiometric fields. However, it requires a sufficient set of clear data. Furthermore, meteorological studies require a snow-free albedo to conveniently account for the scenario of a partial snow cover. Hence, it is obligatory to propose albedo values for both bare soil and vegetation. Note that for the sake of homogeneity, the same distinction applies to the emissivity. This constitutes the second approach in which the total albedo product is calculated based on the weighting by the vegetation fraction. A main shortcoming of this other approach is that an independent measurement of soil and vegetation albedos presents a difficult task with remote sensing data, except over large deserts or canopies with full coverage. The use of ground measurements seems inevitable in this context. There exist several advantages, such as the robustness, the consistency, and a flexible use by the modelers, so that the second approach is retained. However, the satellite albedo is used in a verification mode as a diagnosis for both controlling the magnitudes of the barren lands and the total albedo product.

The vegetation emissivity is arbitrarily set to a typical value of 0.97 , and a value of 0.94 is considered for the dry bare soils (compatible with MODIS database, see online at http://www.crseo.ucsb.edu/modis/EMIS/html/ em.html). A vegetation albedo can be correctly attributed per land cover type based on the literature (see previous sections). On the other hand, the computation of a bare soil albedo $\left(\alpha_{\text {soil }}\right)$ is a more difficult task because it is rather sensitive to the material texture, which is caused by both soil mineral composition and organic deposition (Irons et al. 1988). Herein, we use an empirical formula that combines the sand fraction $\left(f_{\text {sand }}\right.$, with a minimum threshold of 0.30 applied to this fraction in the following formula), representing the soil mineral composition, and the fraction of woody and herbaceous vegetation types $\left(f_{\text {woody }}+f_{\text {herbaceous }}\right)$ standing for the organic deposition:

$$
\begin{aligned}
\alpha_{\text {soil }}= & 0.10+\left(0.05+0.30 f_{\text {sand }}\right) \\
& \times\left[1-0.9\left(f_{\text {woody }}+f_{\text {herbaceous }}\right)^{2}\right] .
\end{aligned}
$$

From this equation, the more sand or the less organic material, the brighter the soil. The resulting annual average total albedo is shown in Fig. 8. It shows very little seasonal variation, because it does not take into account the seasonal snow effect [the modification of albedo by snow is part of the parameterization of snowpack in the meteorological or climate model, as in Douville et al. (1995)]. This albedo compares well with the values of Strugnell et al. (2001) derived from global AVHRR datasets. In addition, we can verify our findings with additional satellite-derived albedo collected over Africa (Ba et al. 2001; Pinty et al. 2000). Note that the patterns of the Saharan spatial heterogeneity are appropriately mimicked thanks to a trustworthy report of the sand fraction extracted of the FAO database (FAO 1988).

\section{Validation of the LAI and comparison with other datasets \\ a. Validation of the results based on in situ LAI database}

A well-documented database of in situ LAI measurements was recently prepared and made available (see Roujean and Lacaze 2002; Lacaze 2002, manuscript submitted to Int. J. Remote Sens.). It gathers an exhaustive and complete description of measured LAI data that were collected over the whole globe during the last several years using instrumental (indirect) or destructive 


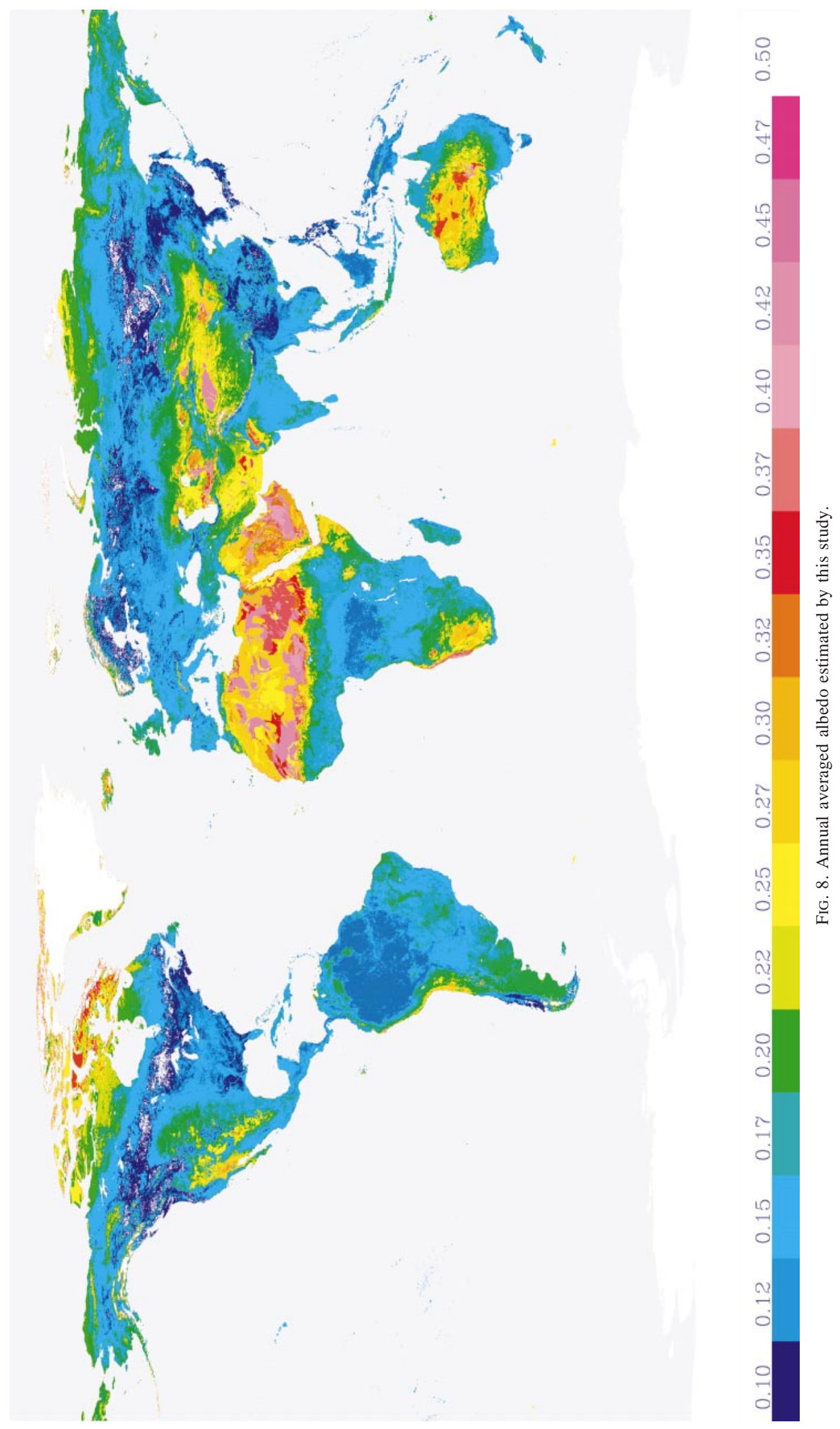



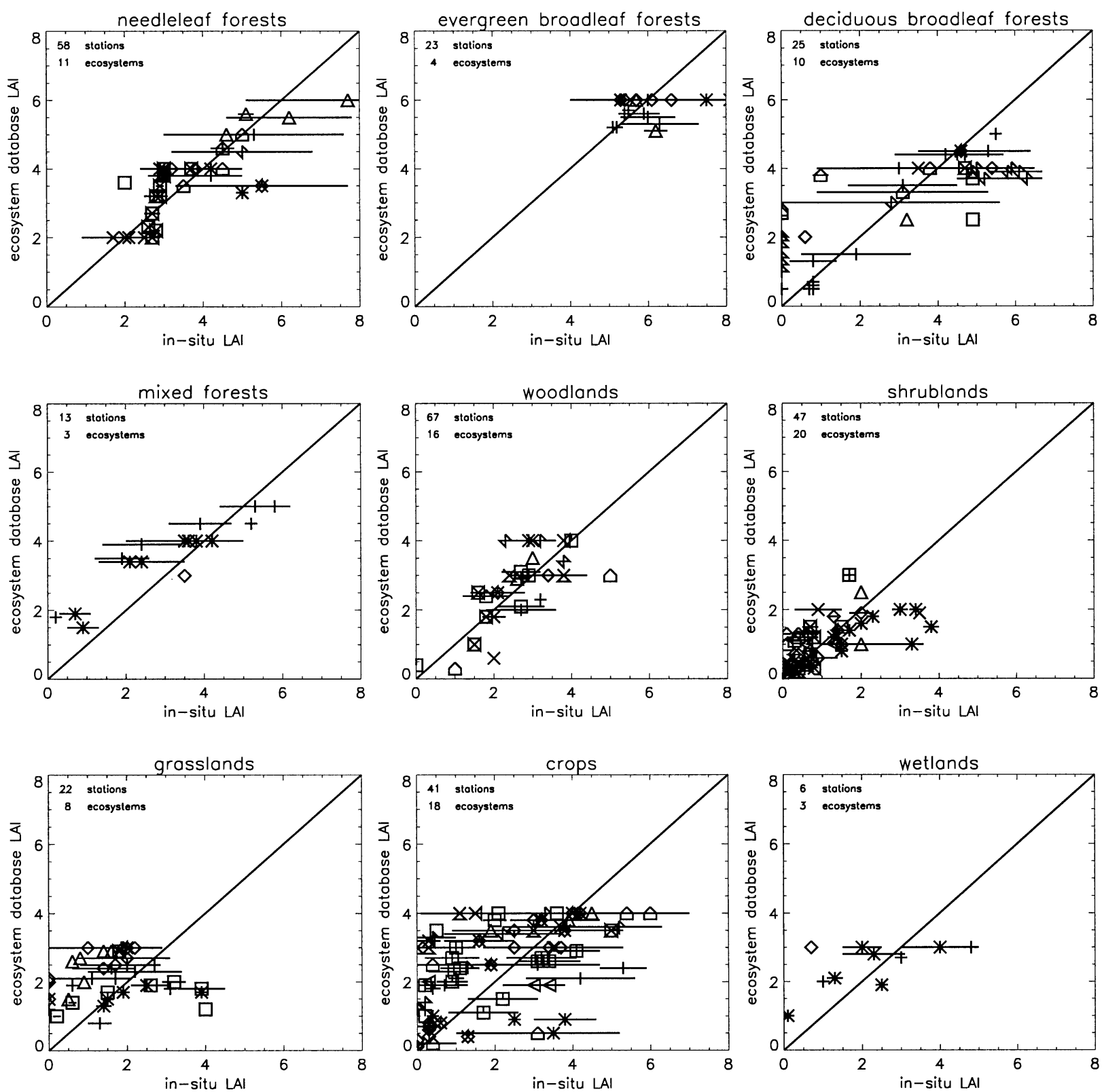

FIG. 9. Comparison of the ecosystem LAI vs the observed LAI, for each month and ecosystem, arranged using nine different land covers. For each graph, each symbol corresponds to the same ecosystem. The same symbol appearing several times on the same graph shows the temporal variability of the ecosystem (the symbol being displayed for each month). Horizontal bars are not error bars, but represent the spatial variability of observations when several sites are available for the same ecosystem and month.

(direct) methods. The North American and European continents were the most densely investigated and sampled. For each acquisition, measured LAI and NDVIderived LAI from the present method were compared. A systematic comparison was carried out for the major land covers (Fig. 9), which gives quite acceptable results (see Table 3). Bias is very low, for all land cover types, and root-mean-square errors are acceptable. The 1:1 line relationship is correctly reproduced (see coefficient of determination $r^{2}$ ) for six land covers, but there are discrepancies for three others: for the evergreen broadleaf forests, a problem arises because of a strong spatial variability in the observations among the same ecosystem, which cannot be captured with our method. For grasslands, it is not so clear. Two stations, showing observations with a large annual amplitude, are not really representative of their ecosystem, which shows a small NDVI signal (not shown). On the other hand, the large scatter for crops is not surprising, since most measurement points are dedicated to one specific crop, and are not necessarily representative at the ecosystem scale. Furthermore, the harvesting is variable, and explains 
TABLE 3. Goodness of fit statistics of ecosystem LAI compared to in situ ground measurements. Ecosystems are arranged according to their land cover.

\begin{tabular}{lccc}
\hline \hline \multicolumn{1}{c}{ Land cover } & $r^{2}$ & $\begin{array}{c}\text { Bias } \\
\left(\mathrm{m}^{2} \mathrm{~m}^{-2}\right)\end{array}$ & $\begin{array}{c}\text { Rmse } \\
\left(\mathrm{m}^{2} \mathrm{~m}^{-2}\right)\end{array}$ \\
\hline Coniferous forests & 0.83 & -0.10 & 0.73 \\
Evergreen broadleaf forests & 0.29 & -0.52 & 1.54 \\
Deciduous broadleaf forests & 0.82 & +0.02 & 1.35 \\
Mixed forests & 0.91 & +0.49 & 0.92 \\
Woodlands & 0.72 & +0.02 & 0.79 \\
Shrublands & 0.72 & 0 & 0.67 \\
Grasslands & 0.09 & +0.48 & 1.26 \\
Crops & 0.53 & +0.33 & 1.49 \\
Wetlands & 0.61 & +0.28 & 1.17 \\
All & 0.81 & +0.12 & 1.15 \\
\hline
\end{tabular}

most of the very low values in the observations (the other being winter values). However, the maximum of our LAI is coherent with the observed values. With the present process, 93 ecosystems worldwide could be validated, with the most for the forest biome, including 30 for Europe.

\section{b. Comparison with ISLSCP2 and POLDER maps}

The LAI maps of the present classification are now compared to other satellite-derived datasets. The one most widely used is from the ISLSCP- 2 at $1^{\circ}$ resolution. The second dataset considered is from the $6-\mathrm{km}$ resolution POLDER global imagery acquired between October 1996 and June 1997. The POLDER LAI was mapped following a physically based approach (Roujean and Lacaze 2002). The results between the three datasets are generally in good agreement for January (Fig. 6) and June (Fig. 7), with a few exceptions. A noticeable difference arises in the case of boreal forests in summer. Our LAI is the largest (equal to $5 \mathrm{~m}^{2} \mathrm{~m}^{-2}$ ), slightly larger than the ISLSCP-2 value, and much larger than the POLDER value (an averaged value of 3 ). At least for North America, numerous in situ data (Chen et al. 1997a) confirm that this maximum LAI of 5 is indeed reasonable. However, it is important to note that all three datasets show a large annual cycle for these forests. Even if the LAI of evergreen needleleaf trees does not show a large annual cycle (a yearly amplitude of $1 \mathrm{~m}^{2}$ $\mathrm{m}^{-2}$ seems acceptable in reality), it is largely amplified in practice by the growth of the understory layer, which can reach an LAI of about $2 \mathrm{~m}^{2} \mathrm{~m}^{-2}$ in the summer (Chen et al. 1997a), but is zero in winter. This is confirmed by the physical approach, for which the LAI in boreal forests is decreased in winter (Roujean and Lacaze 2002). We admit that our LAI value is somewhat underestimated (by approximately $1 \mathrm{~m}^{2} \mathrm{~m}^{-2}$ ) for the eastern Canadian forests. That might be explained by the nonallocation of a specific climate in the work of Koeppe and De Long (1958; see our Fig. 3). It remains that these particular forests were not differentiable with our methodology. In contrast, an ecosystem could be established for the American northwest rainforest that is able to show a unique cycle of LAI. This is not clear in winter for the ISLSCP-2 data, and below the clouds for POLDER. Another difference arises for the equatorial forests. ISLSCP2 is the largest (sometimes more than $7 \mathrm{~m}^{2} \mathrm{~m}^{-2}$ ), while POLDER is smallest (from 3 to 6). Our LAI is in between, ranging from 5 to 6 . These values seem reasonable. Finally, the largest difference between our dataset and both ISLSCP-2 and POLDER is encountered for temperate broadleaf forests in Europe, Russia, and the eastern United States, and some grasslands in Europe when compared to POLDER. In summer, our LAI reaches 4.5-5 $\mathrm{m}^{2} \mathrm{~m}^{-2}$ for forests, 3 for grasslands, while the other datasets have values as large as 6 and 7 over large areas of several square degrees. In situ observations show maximum values in summer around $4.5 \mathrm{~m}^{2} \mathrm{~m}^{-2}$ for such forests (see, e.g., Schmid et al. 2000; Sakai et al. 1997; more information available online at http://www. eosims.esd.ornl.gov/FLUXNET/site_info/stand.html and http://mercury.ornl.gov/ornldaac for the eastern U.S. forest). However, these measurements also show a smallscale spatial variability reaching from 1 to $1.5 \mathrm{~m}^{2} \mathrm{~m}^{-2}$. Still, averaged LAI values of 6 or 7 at a scale of $6 \times 6$ $\mathrm{km}^{2}$ (POLDER) or one squared degree (ISLSCP-2) seem overestimated compared to in situ observations, and are therefore not retained at the ecosystem scale. The question of small-scale spatial variability is adressed in the next paragraph. In general, the new dataset does not show other significant differences in features compared with the other datasets at a large scale. There is good coherence between the three datasets for crops and herbaceous vegetation types.

Nonetheless, some instructive differences and likenesses are observable at the full POLDER resolution. At this finer scale, it is possible to assess the capability of our LAI to reproduce a realistic spatial distribution. When the spatial heterogeneity of the LAI is caused by the juxtaposition of different land covers, the ecosystem approach captures the heterogeneity. However, when this heterogeneity takes place within the same ecosystem, the LAI of the present study fails to reproduce the spatial distribution as compared to POLDER. This is due to the underlying assumptions that an ecosystem should be, by definition, homogeneous with only one land cover type. This intraecosystem variability, as viewed by POLDER (and sometimes sampled by in situ observations, especially in temperate forests), is often of the order of $1 \mathrm{~m}^{2}$ $\mathrm{m}^{-2}$, but it is larger over equatorial forests. Crops do not show a significant internal variability at a scale of $6 \mathrm{~km}$ (the POLDER resolution). This does not mean that there is no variability at smaller scales, and this should be investigated with new high resolution satellite instruments [MODIS (http://modis.gsfc.nasa.gov) and VEGETATION (http://www.spotimage.fr/data/images/vege/ VEGETAT/book_1/DEBUT.HTM)]. Finally, the LAI variability due to cover variability is most often quite large compared to the intraecosystem variability, and this validates our approach. Otherwise, an advantage (of primary 
importance for further meteorological or climate modeling) of the present LAI is that it has no missing data contrary to POLDER LAI. The missing data are due to a high frequency of cloud coverage in the winter hemisphere.

\section{Indirect validation in a climate model \\ a. Validation strategy}

In order to validate the new surface parameter dataset, we performed two 10-yr climate simulations in which we used surface conditions issued, respectively, from the usual land parameters (Wilson and Henderson-Sellers 1985) and the new surface parameters. The model is version 3 of the climate model ARPEGE/IFS (Déqué et al. 1994). It is a spectral model used in a uniform T106 truncation, with a collocation grid of $120 \times 240$, corresponding to a $1.5^{\circ}$ resolution, and 31 vertical levels. The Interaction Surface-Biosphere-Atmosphere (ISBA; Noilhan and Planton 1989; Mahfouf et al. 1995; Douville et al. 1995) surface scheme is used. SSTs are prescribed and constant from one year to another. Their climatological annual cycle was obtained from the Reynolds observed climatology over the 1970-89 period (Reynolds and Smith 1994). As sea surface temperatures are climatological, the $10 \mathrm{yr}$ of each simulation can be viewed as 10 independent members of an ensemble run.

In order to show the ability of the Ecoclimap dataset to better represent the actual vegetation cover of the surface, the two following parameters have been compared to the observations [Climatic Research Unit (CRU) climatology]: the mean daily maximum temperature $\left(T_{\max }\right)$, and the mean daily minimum temperature $\left(T_{\min }\right)$. The CRU climatology reference is computed over the 1961-90 period (New et al. 1999). The interest in focusing on these temperatures instead of the mean daily temperature $\left(T_{2 \mathrm{~m}}\right)$ is that they allow a more direct validation of the physical processes of the surface energy budget.

The $T_{\max }$ is representative of the maximum diurnal heating, so that it gives information on the ability of the model to correctly handle daytime $Q^{*}$ (via the albedo), and the partitioning of energy between the two turbulent fluxes $Q_{H}$ and $Q_{E}$ (via the vegetation parameters). The $T_{\min }$ focuses on the nocturnal energy budget, and it mostly depends on $Q^{*}$ and $\Delta Q_{s}$. It will then provide information on the correct values of the emissivity and the thermal properties of vegetation and soil. Note that both $T_{\max }$ and $T_{\min }$ are helpful for indirectly validating the water budget, since there is a strong relationship with the water stored in the soil (that influences $Q_{E}$ during the day and the thermal properties of soil at night).

\section{b. Daytime impact}

Figure 10 shows the anomalies with respect to the CRU climatology of $T_{\max }$ for the old (top), the new (middle)
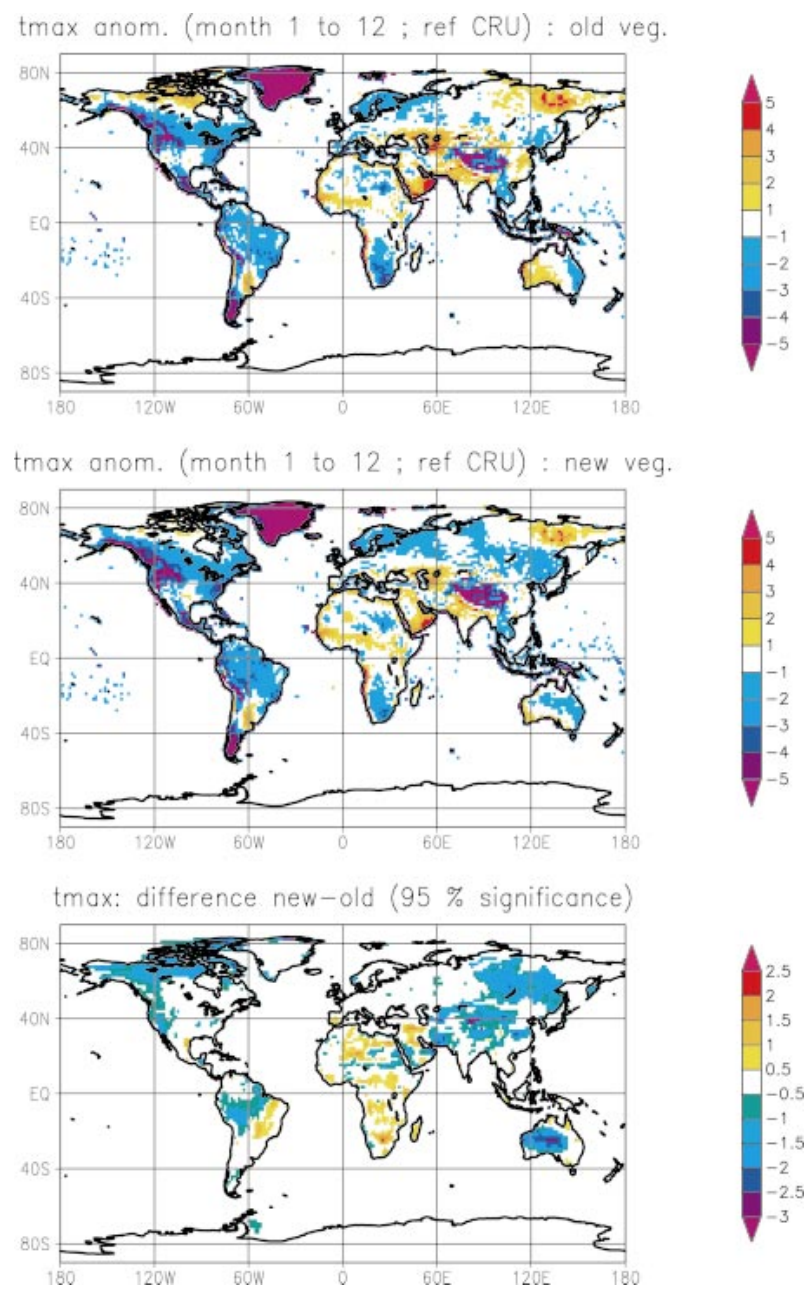

FIG. 10. The 10-yr average of simulated daily maximum surface temperature $\left(T_{\max }\right)$ anomalies compared to the CRU (1961-90) climatology for (a) old and (b) new surface parameters. (c) The difference between the simulations with the new and the old parameters (only differences significant at the 95\% level of a Student's $t$ test are plotted). Intervals are $1 \mathrm{~K}$ for (a) and (b), and $0.4 \mathrm{~K}$ for (c).

simulations, and the difference between the two (bottom). The major impacts of the Ecoclimap database on the daytime energy budget are the following:

1) Over equatorial regions, the forest soil depths are significantly increased. This leads to a summer and autumn cooling of the maximum temperature as the enhanced storage of water maintains significant transpiration all summer. It tends to reduce the bias in summer and to enhance it in autumn.

2) Over tropical regions there is an increase of $T_{\max }$. While the Sahara and the Arabian peninsula increases can be explained by a smaller albedo, other regions seem to be affected by an enhanced stomatal resistance, which reduces transpiration effects. This leads to a better agreement with the CRU climatology, which is possibly related to a better daytime energy budget in these regions. 
3) Arid regions of Australia experience substantial changes in albedo, associated with an enhancement of the vegetation. This leads to a strong cooling (up to $3 \mathrm{~K}$ ), which tends to reduce the southwestern bias while creating a small cold bias over central Australia. The warm bias reduction is the largest during the Australian monsoon. As precipitation fields are also improved (a large bias is totally removed, not shown), one can conclude that the Australian monsoon is better reproduced with the Ecoclimap database.

4) The most noticeable seasonal features (not shown) that do not appear in the annual mean are a strong reduction (reaching more than $3 \mathrm{~K}$ ) of the cold bias over the central and eastern United States in winter, and over northern Russia in the spring.

5) Over mountain or septentrional regions, one notes a cooling of the far northern region of Canada reaching $2 \mathrm{~K}$ with a maximum during summer. The decrease of the stomatal resistance over this region (where woodlands and wooded grasslands replace forests), thus favoring transpiration, can explain this cooling, which leads to a more realistic $T_{\max }$ compared to CRU climatology. On the contrary, the extension of the cooling in the Rocky Mountains along the west coast of Canada leads to a larger bias. The Siberian cooling is maximum in the summer (not shown) where both the soil depth and the LAI are increased leading to more plant transpiration. Compared to the CRU climatology, this is not realistic. On the other hand, the warm bias is reduced over the Gobi Desert, Kazakhstan, and the Iran plateau, due to better albedos.

Finally, changes in the vegetation fraction and the LAI owing to the Ecoclimap classification seem to explain a major part of the surface temperature anomalies, except for the Australian, Asian, and African deserts, where the changes are mainly related to the albedo.

\section{c. Nocturnal impact}

Figure 11 shows anomalies of $T_{\min }$ for the old (top) and the new (middle) simulations, and the difference between the two (bottom). The nocturnal energy balance is much less critical than that for the daytime as a forcing to the atmosphere, but it would be more perturbed by climate warming (through the increase of longwave radiation).

1) There is no impact on equatorial forests.

2) Tropical semiarid regions experience a general cooling, leading to a cold bias in $T_{\text {min }}$ principally located over Brazil, the Guinea coast, the southeast coasts of Africa and India, and causing a reduced warm bias in other regions. Enhancement of the emissivity accounts for approximately a $1-\mathrm{K}$ cooling (increase ranges from 0.010 to 0.015 ). However, a major part of the cooling in the savanna (Africa) and the cerrado (South America) regions can be explained by the
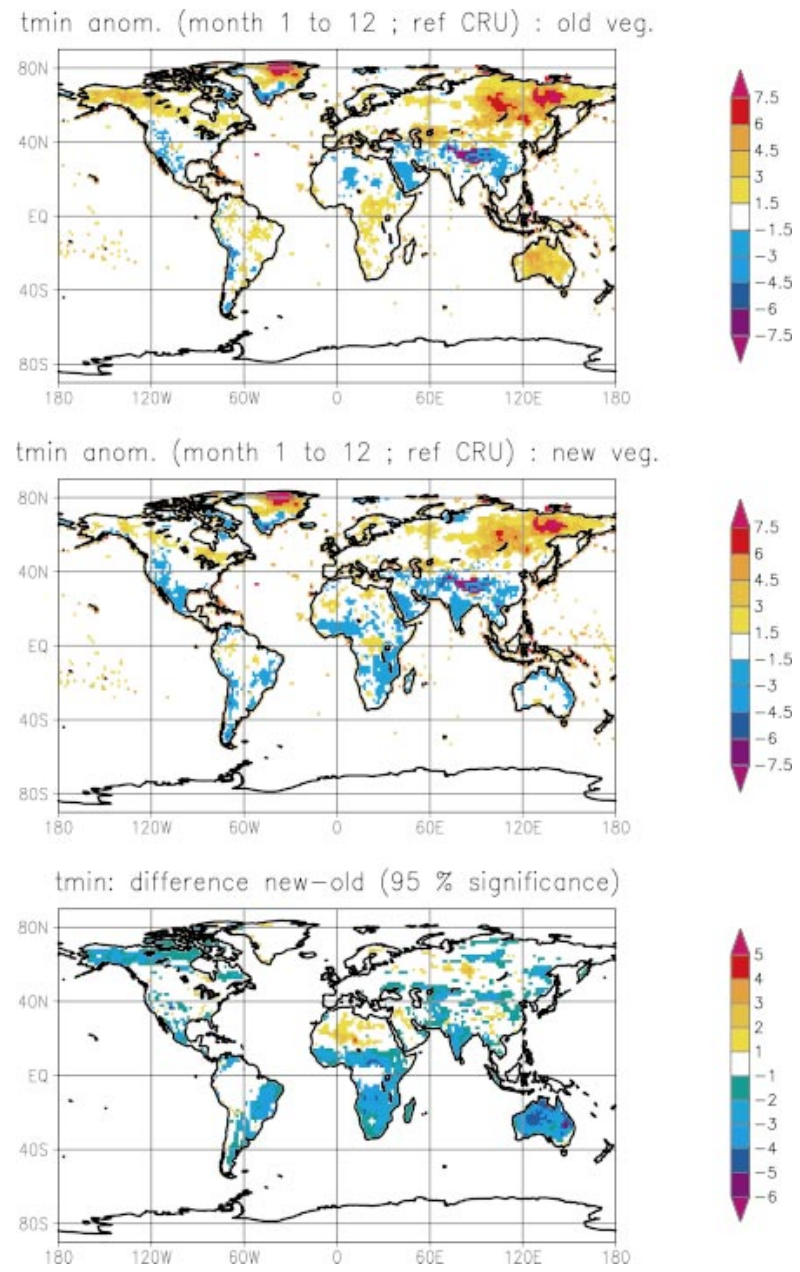

FIG. 11. Same as Fig. 10, except for daily minimum surface temperature $\left(T_{\min }\right)$.

thermal properties of the vegetation. There, trees and herbaceous vegetation coexist (with a majority of the latter type). Trees usually cool much more slowly and limit the nocturnal cooling in such heterogeneous landscapes. This is taken into account in Ecoclimap, but it could not be implemented in the model, because only the thermal properties of the primary vegetation are used (the herbaceous vegetation in this case). This explains the cold bias of the model in these regions.

3) The cooling over the Australian continent contributes to a strong reduction of the bias. It is mainly due to the increased albedo, which reduces the energy storage during the daytime, leading to a global cooling of the deep soil.

4) The southwestern region of China has a warming that is maximum in autumn. This warming corresponds to a reduction in the vegetation fraction. Improvements mentioned for $T_{\max }$ over the central and eastern United States and northern Siberia are also 
seen in the $T_{\min }$. Enhanced storage of heat during the daytime leads to a warmer temperature at night.

5) Northern Canada and, to a lesser extent, northern Siberia, experience a reduction of their strong warm biases in winter $(6-8 \mathrm{~K})$. This improvement is linked to a larger snow fraction in the Douville et al. (1995) snow mantel scheme, caused by the replacement of forest by woodland (the role of snow is minimized under forests because it is under closely packed trees). The larger impact of snow on the thermal properties of the surface therefore explains the larger nocturnal cooling. Note that the impact on the daytime energy budget, through the increase of albedo due to snow, is not so clear, because solar radiation is very low in this period.

\section{d. Statistical results}

In order to more quantitatively measure the impact of the new dataset, root-mean-square errors (rmse) have been calculated for $T_{\min }, T_{\max }$, and the precipitation simulated by the model. These are shown in Fig. 12.

The 10-yr mean is compared to the climatology [CRU for $T_{\min }$ and $T_{\max }$ and Climate Prediction Center (CPC) Merged Analysis of Precipitation (CMAP) for precipitation] for seasonal averages. We have also distinguished the Northern and Southern Hemispheres. For each variable and period, rmse is calculated over all the points where the difference between the two simulations is significant at the $95 \%$ confidence level in order to avoid the acumulation of some non-significant errors in the final result.

One can observe that $T_{\max }$ is more realistic in the new dataset in autumn for the Northern Hemisphere (NH) and in spring and summer for the Southern Hemisphere $(\mathrm{SH})$. It is worse in summer in the NH (because of the bias over the Rocky Mountains and Siberia as mentioned above) and winter for the $\mathrm{SH}$. The $T_{\min }$ is much more realistic in the new dataset, except for spring in the $\mathrm{NH}$. This indirectely shows the global improvement of the representation of the surface energy balance (over the continents) in the model.

In order to illustrate a second-order climate variable (not directly affected by surface parameters), the precipitation rmse has been computed. Results are more questionable since precipitation does not show a clear tendency in favor of one dataset or the other, except for an improvement of the Australian monsoon. Even when increasing the realism of the surface behavior, the atmosphere does not always respond in a more realistic way. This shows the limits of such an exercise.

\section{Conclusions}

A 1-km classification of 215 homogeneous ecosystems was performed using land cover maps. The discrimination inside the same land cover is performed using a climate map and NDVI profiles. In a second step, surface parameters used in SVATs, (e.g., LAI, vegetation fraction, roughness length, minimal stomatal resistance, albedo, and emissivity) are computed using lookup tables. This complete and coherent surface dataset is aimed to be used in any type of atmospheric model, from GCMs for global forecasting and climate studies, to regional climate modeling, down to mesoscale forecasting and research models. The dataset is available online to the research community (http://www.cnrm.fr/gmme/PROJETS/ECOCLIMAP/ page_recoclimap.htm).

- The very fine resolution of the data $(1 \mathrm{~km})$ over the globe allows the initialization of the surface parameters of the models down to the mesogamma (kilometric) scale. Such a resolution already existed in land-use maps, but with this dataset, the vegetation (and urban) parameters (LAI, etc.) are also available. For example, an urban heat island and the associated urban breeze were correctly simulated over Paris, France (see our Fig. 2b) by Lemonsu and Masson (2002) with the MESO-NH French community research model (Lafore et al. 1998).

- The vegetation parameters are deduced from satellite data for each month, climate, and continent. This implies that they can be used in atmospheric numerical models for any location in the world. This was already possible before, but only at a much coarser resolution $\left(1^{\circ}\right)$. This is important both for climate and global weather prediction models (because the resolution of the global models increases), and for the limited area models (because they can be used anywhere at high resolution with data coherent with the actual surface).

- The resolution of the data is also useful for works at much larger scales, for example, for climatic studies, because it contains a fine description of the (climate model) subgrid information. Coherent surface parameters for deforestation scenario studies, for example, are easily computable: the forest can be replaced by crops (or some other cover type) in a region of the world, and then the LAI will be computed using the LAI of crops in this climatic region, instead of the forest values. Then, other surfaces parameters are estimated from this deforested LAI. To obtain an even more realistic scenario, only part of the forest should be removed.

- This dataset can be used to initialize SVATs using the "tile" approach. Different surface parameters are then assigned to, for example, the bare soil, low vegetation, and woody vegetation parts of the grid mesh, allowing the computation of several energy budgets in the same grid mesh.

- Finally, this dataset is very useful for grid-nested models, because the surface will be coherent between all the models. Thus, the larger models will present a low resolution, but they cover a large surface, so the climate information is important, especially if numerous climates are present in the domain. The finer models will cover a smaller area, so the resolution information 
Tmax HN

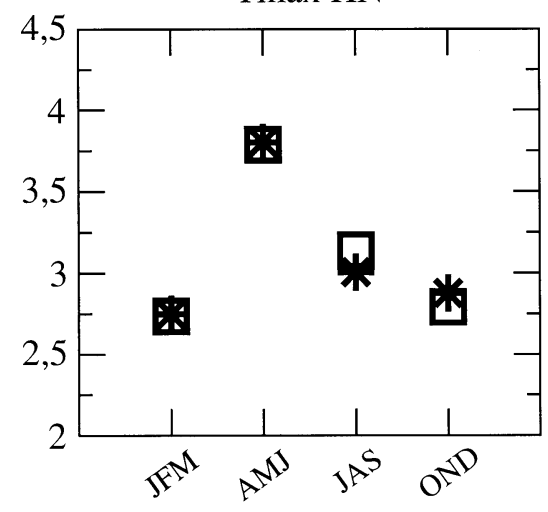

Tmin HN

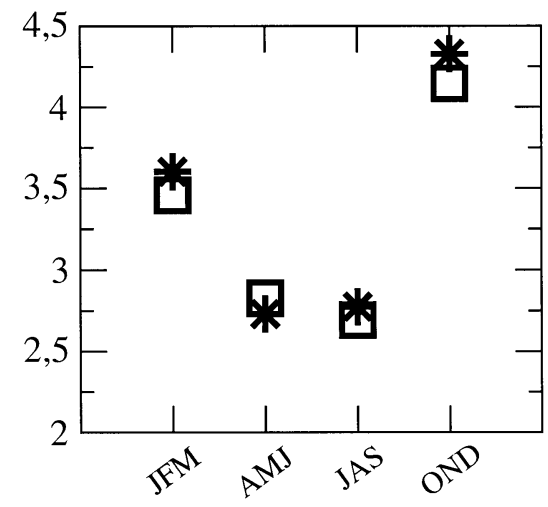

Precipitation HN

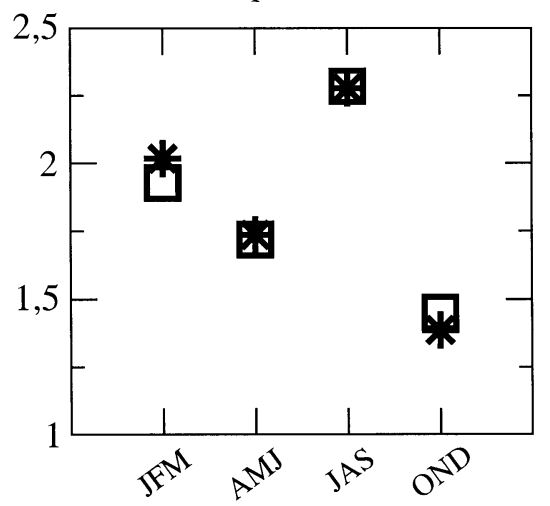

Tmax HS

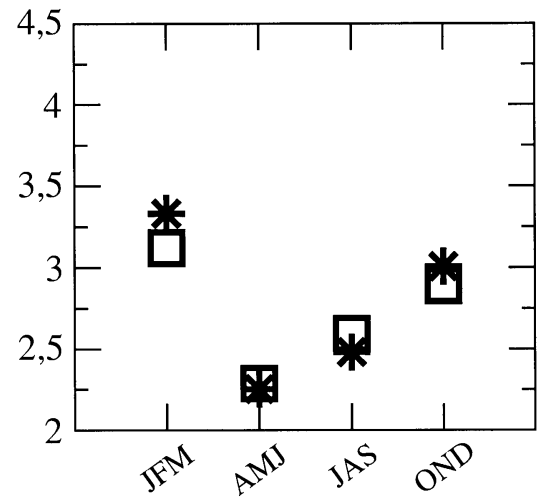

Tmin HS

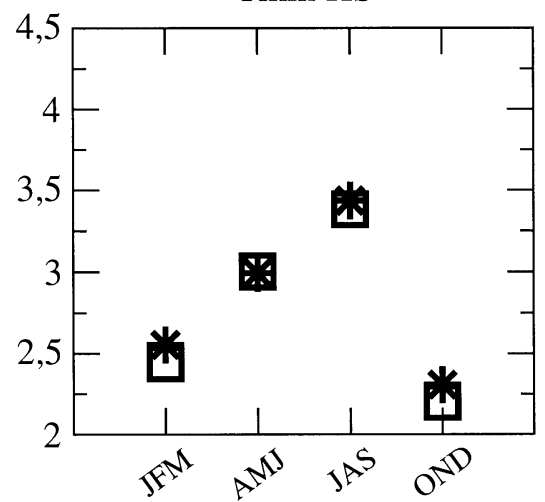

Precipitation HS

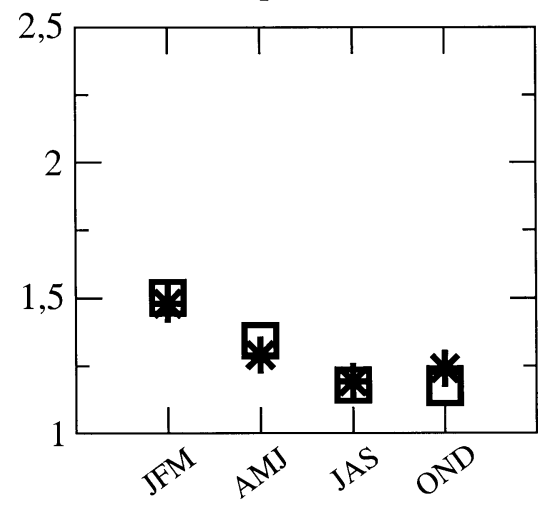

FIG. 12. Rmse for (top) $T_{\max }$, (middle) $T_{\min }$, and (bottom) precipitation calculated for Jan-FebMar, Apr-May-Jun, Jul-Aug-Sep, and Oct-Nov-Dec. Stars correspond to the old dataset and squares to the new one. The left column is for Northern Hemisphere and the right one is for Southern Hemisphere.

is important, but still, this one is completely coherent with the climatic information used in the larger models.

Acknowledgments. We are grateful to the providers of global land cover datasets: the University of Maryland (Department of Geography) and the Eros Data Center. The authors are indebted to Jean-Louis Roujean,
Philippe Bougeault, Hervé Douville, Karine Maynard, and Joel Noilhan for their critical reading of the manuscript, and Aaron Boone who helped with the English. We also thank Météo-France for technical assistance.

\section{REFERENCES}

Asrar, G., M. Fichs, E. T. Kanemasu, and J. L. Hatfield, 1984: Estimating absorbed photosynthetically active radiation and leaf 
area index from spectral reflectance in wheat. Agron. J., 76, 300306.

Avissar, R., and R. A. Pielke, 1989: A parameterization of heterogeneous land surface for atmospheric numerical models and its impact on regional meteorology. Mon. Wea. Rev., 117, 21132136.

Ba, M. B., S. E. Nicholson, and R. Frouin, 2001: Satellite-derived surface radiation budget over the African continent. Part II: Climatologies of the various components. J. Climate, 14, 60-76.

Baret, F., and G. Guyot, 1991: Potentials and limits of vegetation indices for LAI and APAR assessment. Remote Sens. Environ., 35, 161-173.

Betts, A. K., and J. H. Ball, 1997: Albedo over the boreal forest. J. Geophys. Res., 102 (D24), 28 901-28 909.

Bougeault, P., J. Noilhan, P. Lacarrère, and P. Mascart, 1991: An experiment with an advanced surface parameterization in a mesobeta-scale model. Part I: Implementation. Mon. Wea. Rev., 119, 2358-2373.

Brown, J. F., T. R. Loveland, J. W. Merchant, B. C. Reed, and D. O. Ohlen, 1993: Using multisource data in global land cover characterization: Concepts, requirements and methods. Photogram. Eng. Remote Sens., 59, 977-987.

Buermann, W., Y. Wang, J. Dong, L. Zhou, X. Zeng, R. E. Dickinson, C. S. Potter, and R. B. Myneni, 2002: Analysis of a multiyear global vegetation leaf area index data set. J. Geophys. Res., 107, 4646, doi:10.1029/2001JD000975.

Calvet, J.-C., R. Santos-Alvala, G. Jaubert, C. Delire, C. Nobre, I. Wright, and J. Noilhan, 1997: Mapping surface parameters for mesoscale modeling in forested and deforested southwestern amazonia. Bull. Amer. Meteor. Soc., 78, 414-423.

— , J. Noilhan, J.-L. Roujean, P. Bessemoulin, M. Cabelguenne, A. Olioso, and J. P. Wigneron, 1998: An interactive vegetation SVAT model tested against data from six contrasting sites. Agric. For. Meteor., 92, 73-95.

Canadell, J., R. B. Jackson, J. R. Ehleringer, H. A. Mooney, O. E. Sala, and E.-D. Schulze, 1996: Maximum rooting depth of vegetation types at the global scale. Oecologia, 108, 583-595.

Champeaux, J. L., D. Arcos, E. Bazile, D. Giard, J. P. Goutorbe, F. Habets, J. Noilhan, and J. L. Roujean, 2000: AVHRR-derived vegetation mapping over western Europe for use in numerical weather prediction models. Int. J. Remote Sens., 21, 1183-1199.

Chen, J. M., P. M. Rich, S. T. Gower, J. M. Norman, and S. Plummer, 1997a: Leaf Area Index of boreal forests: Theory, techniques and measurements. J. Geophys. Res., 102 (D24), 29 429-29 443.

Chen, T. H., and Coauthors, 1997b: Cabauw experimental results from the project for intercomparison of land-surface parameterization schemes. J. Climate, 10, 1194-1215.

Culf, A. D., G. Fisch, and M. G. Hodnett, 1995: The albedo of Amazonian forest and ranchland. J. Climate, 8, 1544-1554.

— J. L. Esteves, A. de O. Marques Filho, and H. R. da Rocha, 1996: Radiation, temperature and humidity over forest and pasture in Amazonia. Amazon Deforestation and Climate, J. H. C. Gash et al., Eds., John Wiley and Sons, 175-191.

Defries, R. S., M. C. Hansen, and J. R. G. Townshend, 2000: Global continuous fields of vegetation characteristics: A linear mixture model applied to multi-year $8 \mathrm{~km}$ AVHRR data. Int. J. Remote Sens., 21, 1389-1414

Delire, C., J.-C. Calvet, J. Noilhan, I. Wright, A. Manzi, and C. Nobre, 1997: Physical properties of Amazonian soils: A modeling study using the Anglo-Brazilian Amazonian climate observation study data. J. Geophys. Res., 102 (D25), 30 119-30 133.

Déqué, M., C. Dreveton, A. Braun, and D. Cariolle, 1994: The ARPEGE/IFS atmosphere model: A contribution to the French Community climate modelling. Climate Dyn., 10, 249-266.

Dorman, J. L., and P. J. Sellers, 1989: A global climatology of albedo, roughness length and stomatal resiatance for atmospheric general circulation models as represented by the Simple Biosphere Model (SiB). J. Appl. Meteor., 28, 833-854.

Douglas, B. C., 2001: Modeling the impact of land surface degra- dation on the climate of tropical North Africa. J. Climate, 14, 1809-1822.

Douville, H., J.-F. Royer, and J.-F. Mahfouf, 1995: A new snow parameterization for the Météo-France climate model. Part II: Validation in a 3-D GCM experiment. Climate Dyn., 12, 37-52.

EC, 1995: Regionalization and stratification of European forest ecosystems. Internal special publication of the Joint Research Centre of the European Commission, S.I.P.95.44, EC, SAI, EMAP, Italy, 69 pp.

Eidenshink, J. C., and J. L. Faundeen, 1994: The 1 km AVHRR global land data set-First stages in implementation. Int. J. Remote Sens., 15, 3443-3462.

FAO, 1988: UNESCO soil map of the world. World Soil Resources Rep. 60, Rome, Italy.

Gash, J. H. C., W. J. Shuttleworth, C. R. Llyod, J.-C. André, J.-P. Goutorbe, and J. Gelpe, 1989: Micrometeorological measurements in Les Landes forest during HAPEX-MOBILHY. Agric. For. Meteor., 46, 131-147.

Grant, I. F., A. J. Prata, and R. P. Cechet, 2000: The impact of the diurnal variation of albedo on the remote sensing of the daily mean albedo of grassland. J. Appl. Meteor., 39, 231-244.

Gutman, G. G., 1999: On the use of long-term global data of land reflectances and vegetation indices derived from the Advanced Very High Resolution Radiometer. J. Geophys. Res., 104 (D6), 6241-6255.

Hansen, M. C., R. S. DeFries, J. R. G. Townshend, and R. Sohlberg, 2000: Global land cover classification at $1 \mathrm{~km}$ spatial resolution using a classification tree approach. Int. J. Remote Sens., 21, 1331-1364.

Heymann, Y., and Coauthors, 1993: CORINE land cover: Technical guide. Environment, nuclear safety and civil protection series, Commission of the European Communities, Office for Official Publication of the European Communities, Luxembourg, 144 pp.

Irons, J. R., K. J. Ranson, and C. S. T. Daughtry, 1988: Estimating the big bluestem albedo from directional reflectance measurements. Remote Sens. Environ., 25, 185-199.

Jacquemin, B., and J. Noilhan, 1990: Validation of a land surface parameterization using the HAPEX-MOBILHY dataset. Bound. Layer Meteor., 52, 93-134.

Kanemasu, T., U. D. Rosenthal, R. J. Stone, and L. R. Stone, 1977: Evaluation of an evapotranspiration model of corn. J. Agron., 69, 461-464.

Knyazikhin, Y., J. V. Martonchik, R. B. Myneni, D. J. Diner, and S. W. Running, 1998: Synergistic algorithm for estimating vegetation canopy leaf area index and fraction of absorbed photosynthetically active radiation from MODIS and MISR data. $J$. Geophys. Res., 103, 32 257-32 276.

Koeppe, C. E., and G. C. De Long, 1958: Weather and Climate. McGraw-Hill, 341 pp.

Koster, R., and M. Suarez, 1992: Modeling the land surface boundary in climate models as a composite of independent vegetation stands. J. Geophys. Res., 97, 2697-2715.

Lacaze, R., J. M. Chen, J. L. Roujean, and S. G. Leblanc, 2001: Retrieval of vegetation clumping index using hot spot measured by POLDER instrument. Remote Sens. Environ., 78, 1-12.

Lafore, J. P., and Coauthors, 1998: The Meso-NH Atmospheric Simulation System. Part I: Adiabatic formulation and control simulations. Ann. Geophys., 16, 90-109.

Lemonsu, A., and V. Masson, 2002: Simulation of a summer urban breeze over Paris. Bound.-Layer Meteor., 104, 463-490.

Loveland, T. R., and A. S. Belward, 1997: The IGBP-DIS global 1 $\mathrm{km}$ land cover data set, DISCover: First results. Int. J. Remote Sens., 18, 3289-3295.

- B. C. Reed, J. F. Brown, D. O. Ohlen, Z. Zhu, L. Yang, and J. W. Merchant, 2000: Development of a global land cover characteristics database and IGBP DISCover from $1 \mathrm{~km}$ AVHRR data. Int. J. Remote Sens., 21, 1303-1330.

Mahfouf, J. F., A. O. Manzi, J. Noilhan, H. Giordani, and M. Déqué, 1995: The land surface scheme ISBA within the METEO- 
FRANCE climate model ARPEGE. Part I: Implementation and preliminary results. J. Climate, 8, 2039-2057.

Masson, V., 2000: A physically based scheme for the urban energy budget in atmospheric models. Bound.-Layer Meteor., 94, 357 397.

, C. S. B. Grimmond, and T. R. Oke, 2002: Evaluation of the Town Energy Balance (TEB) scheme with direct measurements from dry districts in two cities. J. Appl. Meteor., 41, 1011-1026.

Melillo, J. M., I. C. Prentice, G. D. Farquhar, E. D. Schulze, and O. E. Sala, 1995: Terrestrial biotic responses to environmental change and feedbacks to climate. Climate Change 1995: The Science of Climate Change, J. T. Houghton et al., Eds., Cambridge University Press, $572 \mathrm{pp}$.

Mucher, C. A., and Coauthors, 2001: Development of a consistent methodology to derive land cover information on a European scale from remote sensing for environmental modeling. The PELCOM Report, Centre for Geo-Information (CGI), Rep. 6, Alterra, Wageningen, $160 \mathrm{pp}$.

New, M., M. Hulme, and P. D. Jones, 1999: Representing twentieth century space-time climate variability. Part I: Development of a 1961-90 mean monthly terrestrial climatology. J. Climate, 12, $829-856$.

Noilhan, J., and S. Planton, 1989: A simple parameterization of land surface processes for meteorological models. Mon. Wea. Rev., 117, 536-549.

__ , and P. Lacarrère, 1995: GCM grid-scale evaporation from mesoscale modeling. J. Climate. 8, 206-223.

$\ldots, \ldots$, and P. Bougeault, 1991: An experiment with an advanced surface parameterization in a mesobeta-scale model. Part III: Comparison with the HAPEX-MOBILHY dataset. Mon. Wea. Rev., 119, 2394-2413.

Pinty, B., F. Roveda, M. M. Verstraete, N. Gobron, Y. Govaerts, J. V. Martonchik, D. J. Diner, and R. A. Kahn, 2000: Surface albedo retrieval from meteosat. 2. Applications. J. Geophys. Res., 105 (D14), 18 113-18 134.

Pitman, A. J., and Coauthors, 1999: Key results and implications from phase 1(c) of the Project for Intercomparison of Landsurface Parameterization Schemes. Climate Dyn., 15, 673-684.

Reynolds, R. W., and T. M. Smith, 1994: Improved global sea surface temperature analyses using optimum interpolation. J. Climate, 7, 929-948.

Richardson, 1922: Weather Prediction by Numerical Process. Cambridge University Press, $236 \mathrm{pp}$.
Roujean, J.-L., and R. Lacaze, 2002: Global mapping of vegetation parameters from POLDER multi-angular measurements for studies of surface-atmosphere interactions: A pragmatic method and its validation. J. Geophys. Res., 107, 4150, doi:10.1029/ 2001JD000751.

Sakai, R. K., D. R. Fitzjarrald, and K. E. Moore, 1997: Detecting leaf area and surface resistance during transition seasons. Agric. For. Meteor., 84, 273-284.

Schmid, H. P., C. S. B. Grimmond, F. Cropley, B. Offerle, and H.B. Su, 2000: Measurements of $\mathrm{CO} 2$ and energy fluxes over a mixed hardwood forest in the mid-western United States. Agric. For. Meteor., 103, 357-374.

Sellers, P. J., S. O. Los, C. J. Tucker, C. O. Justice, D. A. Dazlich, G. J. Collatz, and D. A. Randall, 1994: A global 1 by 1 degree NDVI data set for climate studies. Part 2: The generation of global fields of terrestrial biophysical parameters from the NDVI. Int. J. Remote Sens., 15, 3519-3545.

— ical effects of doubled atmospheric CO2 on climate. Science, 271, 1402-1406.

Shuttleworth, W. J., and Coauthors, 1984: Observations of radiation exchange above and below amazonian forest. Quart. J. Roy. Meteor. Soc., 110, 1143-1162.

Strugnell, N. C., W. Lucht, and C. Schaaf, 2001: A global albedo data set derived from AVHRR data for use in climate simulations. Geophys. Res. Lett., 28, 191-194.

van den Hurk, B., P. Viterbo, A. Beljaars, and A. Betts, 2000: Offline validation of the ERA40 surface scheme. European Centre for Medium-Range Weather Forecasts Tech. Memo. 295, 42 pp.

Wetzel, P. J., and A. Boone, 1995: A parameterization for land-cloudatmosphere exchange (PLACE): Documentation and testing of a detailed process model of the partly cloudy boundary layer over heterogeneous land. J. Climate, 8, 1810-1837.

Wilson, M. F., and A. Henderson-Sellers, 1985: Cover and soil datasets for use in general circulation models. J. Climatol., 5, 119143.

Woodward, F. I., 1987: Climate and Plant Distribution. Cambridge University Press, $174 \mathrm{pp}$.

Wright, I. R., and Coauthors, 1996: Towards a GCM surface parameterization of Amazonia. Amazon Deforestation and Climate, J. H. C. Gash et al., Eds., John Wiley and Sons, 473-504.

Zhao, M., and A. J. Pitman, 2000: The regional scale impact of land cover change simulated with a climate model. Int. J. Climatol., 22, 271-290. 